\title{
EL HORMIGÓN DE ALTA RESISTENCIA EN LA EDIFICACIÓN. TIPOLOGÍA ESTRUCTURAL
}

\section{(HIGH PERFORMANCE CONCRETE IN BUILDINGS. STRUCTURAL TYPOLOGY)}

\author{
Jesús Gómez Hermoso, Dr. Ingeniero de Caminos, Canales y Puertos \\ Fomento de Construcciones y Contratas, S. A.
}

ESPAÑA

Fecha de recepción:24-IV-98

\begin{abstract}
RESUMEN
En el presente artículo se realiza una descripción de algunas de las últimas realizaciones internacionales de edificios proyectados y construidos con estructura de hormigón de alta resistencia (HAR). Se detalla y analiza la tipología general y los elementos estructurales que la constituyen. Finalmente se obtiene una serie de conclusiones sobre criterios generales de proyecto que podrian seguirse para futuras actuaciones.
\end{abstract}

\section{SUMMARY}

The present note makes a description about the last international buildings designed and constructed with high performance concrete (HPC). The general typology and the structures elements are detailed and analysed. Finally we had some conclusions about general design criteria that we could follow for future actions.

\section{Introducción}

Hasta hace unos 20 años, y desde la irrupción de los rascacielos dentro del paisaje urbano, la estructura metálica ha sido la tipología fundamental por lo que se refiere al material constituyente de la misma. Sin embargo, el empleo del hormigón como material base en las estructuras de los edificios altos se ha incrementado notablemente en los últimos años. El principal factor que ha permitido esta evolución ha sido el incremento producido en las características mecánicas del mismo. Valores entre 60 y $80 \mathrm{MPa}$ son actualmente fáciles de obtener y con una dosificación aún más estudiada, junto a las adiciones de humo de sílice, se pueden alcanzar valores superiores a los 80 ó $100 \mathrm{MPa}$.

Un dato objetivo que confirma el hecho comentado en el párrafo anterior se obtiene del análisis de la relación de los "100 edificios más altos del mundo" (Council on Tall Buildings and Urban Habitat, 1998). Entre éstos se encuentran 17 construidos en los años 70, 27 en los 80 y 42 en los 90. Los porcentajes de edificios construidos con estructura de acero, hormigón o mixta se pueden ver en la tabla 1 .
Como puede apreciarse, se produce no sólo un descenso del porcentaje de edificios construidos con estructura metálica y un aumento de los de estructura de hormigón, sino que el número de estos últimos llega a ser superior al de los primeros. Fuera de este ámbito de construcciones privilegiadas, como se podrá comprobar más adelante, también se reproduce este hecho.

El hormigón de alta resistencia (en adelante HAR) puede considerarse como un tipo particular de hormigón de altas prestaciones (en adelante HAP). En éste no sólo puede ser la alta resistencia una de sus características, sino también la superior durabilidad. En el caso que nos compete, en su aplicación a las estructuras de edificios altos es, sin embargo, su mayor resistencia y las consecuencias que de ella se derivan el parámetro más significativo. Es por ello por lo que en el presente artículo nos referiremos siempre al primero (HAR), aunque también lleva implícita la mejora de otras características propias de este material.

A pesar de la tendencia indicada en el campo de los edificios altos, en España las realizaciones con este tipo de material 
TABLA 1

\begin{tabular}{|c|c|c|c|c|}
\hline DÉCADA & N $^{\circ}$ EDIFICIOS & ACERO (\%) & HORMIGÓN (\%) & MIXTA (\%) \\
\hline \hline $70 \mathrm{~s}$ & 17 & 76 & 12 & 12 \\
\hline $80 \mathrm{~s}$ & 27 & 41 & 15 & 44 \\
\hline $90 \mathrm{~s}$ & 42 & 28 & 36 & 36 \\
\hline
\end{tabular}

se reducen al edificio "Natura Playa", en Alicante, cuya estructura se encuentra constituida con un hormigón tipo $\mathrm{H}-700$ en pilares y otro tipo $\mathrm{H}-250$ en forjados. El objetivo fundamental del presente documento es el de mostrar algunas de las últimas realizaciones internacionales en este campo estructural, así como obtener algunas conclusiones que permitan incrementar nuestro conocimiento del mismo y contar con unos criterios avalados por la experiencia, aunque sea ajena.

\section{Comparación con otros materiales}

Las alternativas que se plantean habitualmente en este tipo de edificios son la estructura metálica y la constituida con HAR, entendiendo por éste el que alcanza una resistencia característica superior a los $50 \mathrm{MPa}$.

De esta última se pueden subrayar las siguientes ventajas frente a la primera:

-Mayor rigidez y, por tanto, mejor comportamiento frente a acciones horizontales.

-Mayor amortiguamiento intrínseco.

-Menor coste del material.

-En algunas ocasiones, condicionantes locales y de mercado dificultan el acceso a elementos metálicos en la cantidad necesaria; los materiales constitutivos del hormigón prácticamente siempre están accesibles con la calidad mínima requerida.

-Más fácil conservación, sobre todo en estructuras expuestas a la acción de los agentes medioambientales.

-Mejor comportamiento frente a la acción del fuego.

Frente a estos argumentos la tipología metálica puede esgrimir, básicamente, una mayor rapidez de ejecución.

Una tercera alternativa, en realidad una variante de la del HAR, es la estructura de hormigón normal, entendiendo por tal aquél cuya resistencia característica es igual o inferior a $50 \mathrm{MPa}$. Sin embargo, y aunque en el proyecto y ejecución de edificios altos se están empleando este tipo de hormigo- nes, los primeros presentan frente a ellos las siguientes ventajas:

-Las secciones de los pilares (elementos dimensionados, básicamente, frente a esfuerzos de compresión) son más reducidas.

-Su módulo de deformación es más elevado y, por tanto, tienen un menor acortamiento debido a esfuerzos axiles.

-La deformación de los elementos estructurales horizontales (vigas y forjados), para un mismo canto, es menor.

-El peso propio global de la estructura es inferior, pudiendo suponer una cierta reducción de la cimentación.

-El plazo de ejecución de la obra se puede ver reducido al permitir menor tiempo de encofrado, tanto de elementos horizontales como de muros y pilares.

-Aumento de la vida útil de la estructura del edificio. El incremento de la resistencia característica del hormigón lleva asociada una mayor compacidad y, por tanto, una mayor resistencia frente al ataque de agentes agresivos externos al mismo.

Frente a estos argumentos, el "hormigón normal" presenta un mejor conocimiento tecnológico (dosificación, comportamiento a medio y largo plazo, ...) y un precio unitario inferior, si bien el coste total de la estructura no se reduce en la misma proporción que éste, ya que los volúmenes de hormigón empleados son superiores.

\section{Realizaciones internacionales}

La distribución geográfica de este tipo de construcciones se encuentra centrada en tres zonas: Norteamérica (fundamentalmente Estados Unidos), Europa occidental y Sureste asiático. Aunque en la primera se produjeron las realizaciones iniciales y en la segunda se continuaron sus pasos con algunos años de retraso, es en el continente asiático donde se están desarrollando los últimos proyectos.

A continuación se realizará una descripción de la estructura de cada uno de los edificios seleccionados, así como un comentario de algunos aspectos particulares de la misma. 


\subsection{South Wacker Drive}

Este edificio, situado en Chicago y acabado en 1990, tiene 65 plantas y una altura de $293 \mathrm{~m}$. La disposición de su planta varía a lo largo de su altura, siendo un exágono irregular en las inferiores y un octógono en las superiores, tal y como puede apreciarse en la figura 1.

Antes de optar por una solución estructural se plantearon tres alternativas:

-Estructura general del edificio mixta de acero y hormigón, con el núcleo central compuesto por muros de hormigón armado.

-Estructura completa de hormigón armado.

-Pórticos de estructura metálica con un núcleo central rígido de hormigón armado.

Por razones técnicas y económicas se eligió la segunda solución.

La cimentación está constituida por una losa de 2,40 m de espesor, situada sobre 26 pilotes con diámetros entre 1,80 y $2,10 \mathrm{~m}$, empotrados en el lecho de roca $1,80 \mathrm{~m}$.

El núcleo central está formado por muros formando " $\mathrm{C}$ " o "I" en planta. Los espesores de los mismos varían según la altura entre 0,76 y $0,46 \mathrm{~m}$ para las almas, y entre 0,91 y 0,30 para las alas.

El forjado está constituido por vigas de 14,6 m de longitud, sobre las que se sitúan vigas pretensadas prefabricadas con unas luces de 5,80 y 10,00 m. Estas últimas recogen una losa de $0,12 \mathrm{~m}$ de espesor hormigonada in situ.

Para disminuir los efectos diferenciales de retracción y fluencia que pudieran producirse sobre los pilares, se han distribuido de tal forma que la carga y las tensiones a las que se encuentran sometidos sean aproximadamente iguales.

El hormigón empleado es variable en función de la altura a la que se encuentre el elemento estructural, disminuyendo su resistencia de proyecto a medida que se asciende. Los tipos empleados son los siguientes:

-Pilares: $84 \mathrm{MPa}$ en las 13 plantas inferiores; $42 \mathrm{MPa}$ en la planta más elevada, disminuyendo progresivamente entre ambos límites.

-Muros (núcleo central): 64 a $56 \mathrm{MPa}$.

-Forjados: $63 \mathrm{MPa}$ en las plantas inferiores; $52,5 \mathrm{MPa}$ en las plantas superiores.

Sobre las armaduras de acero dispuestas en las secciones de hormigón debe indicarse que en las plantas sótano, y en todos aquellos elementos estructurales que pudieran verse sometidos al ataque de agentes químicos o sales anticongelantes, se encontraban protegidas mediante un baño de resina epoxi.

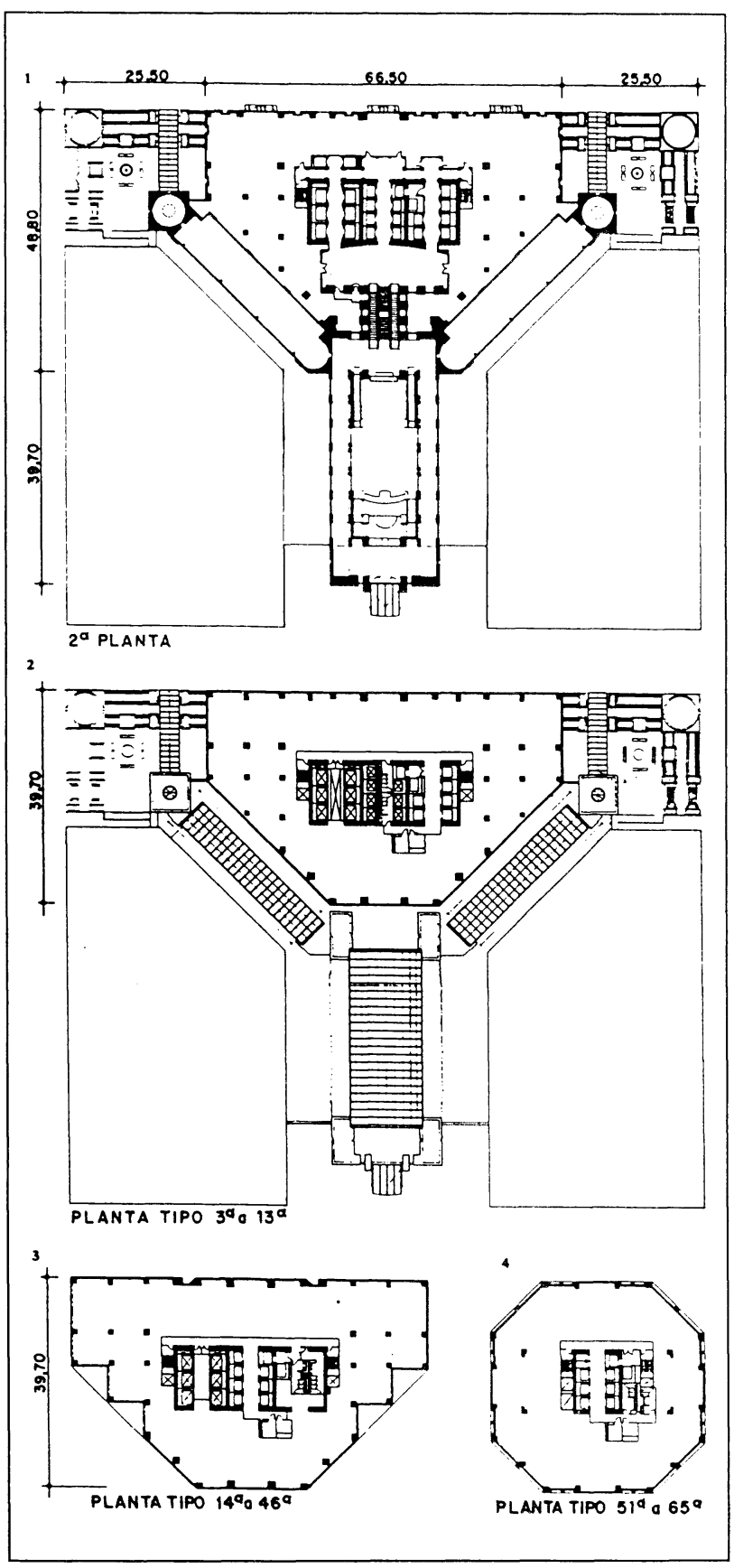

Figura l 


\subsection{Nations Bank Corporate Center}

Este edificio, terminado de construir en 1992, se encuentra en Charlotte, North Carolina, U.S.A. Tiene 65 plantas y una altura de $265 \mathrm{~m}$. Las dimensiones de su planta baja son las de un cuadrado de $52 \mathrm{~m}$ de lado, variando su forma con la altura hasta llegar a otro de $9 \mathrm{~m}$ de lado en las últimas plantas (Foto 1).

El esquema estructural responde a un núcleo central formado por muros de hormigón y una corona perimetral de pilares en la fachada del edificio. Estos pilares, tal y como se aprecia en la figura 2, tienen una disposición de "tubo" hasta la planta $13^{\mathrm{a}}$, cuatro pórticos unidos por esquinas Vierendeel entre las plantas $13^{\mathrm{a}}$ y $43^{\mathrm{a}}$, y cuatro pórticos independientes entre las plantas $43^{\mathrm{a}}$ y $60^{\mathrm{a}}$. El reparto de esfuerzos entre ambos tipos de elementos verticales es tal que el núcleo central recoge, básicamente, los esfuerzos cortantes debidos a viento y sismo, mientras los pilares absorben, fundamentalmente, esfuerzos axiles de compresión.

Los pilares perimetrales, como se puede ver en la planta tipo de la figura 3, están separados unos $3,00 \mathrm{~m}$, variando su sección entre $0,60 \times 0,95 \mathrm{~m}$ en las plantas inferiores y $0,60 \times 0,60$ m en las superiores. Los muros del núcleo central varían sus dimensiones, igualmente, entre $0,60 \times 5,50$ y $0,60 \times 0,90 \mathrm{~m}$.

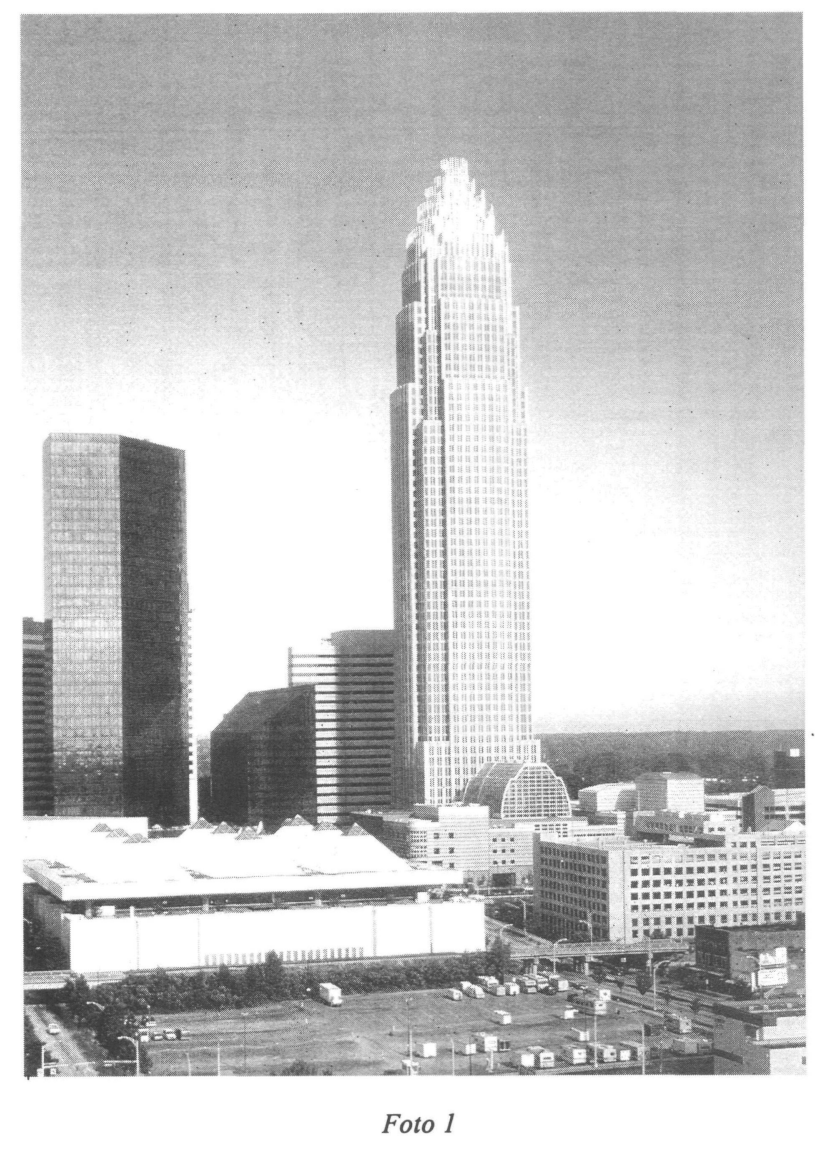

El forjado está constituido por vigas de $0,45 \mathrm{~m}$ de canto y hasta $14,60 \mathrm{~m}$ de luz, separadas $3,00 \mathrm{~m}$, sobre las que se hormigona una losa de $0,12 \mathrm{~m}$ de espesor.

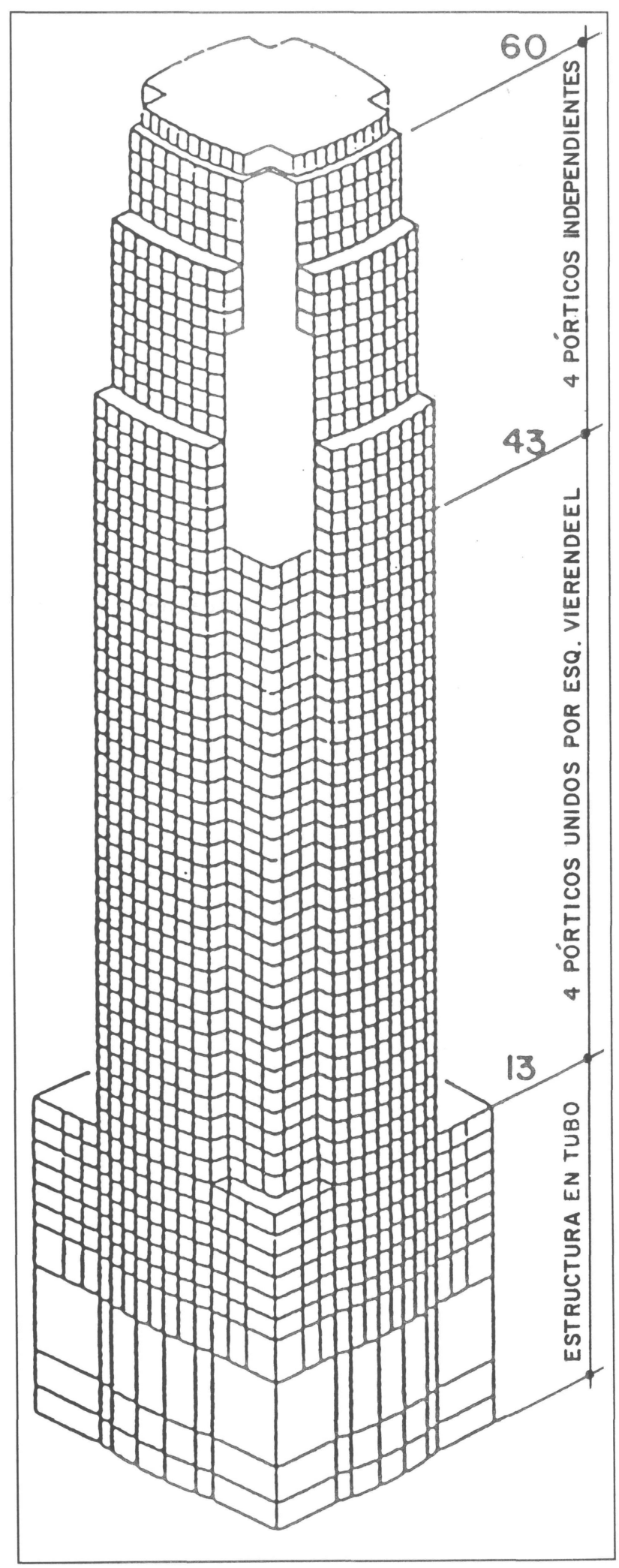

Figura 2 


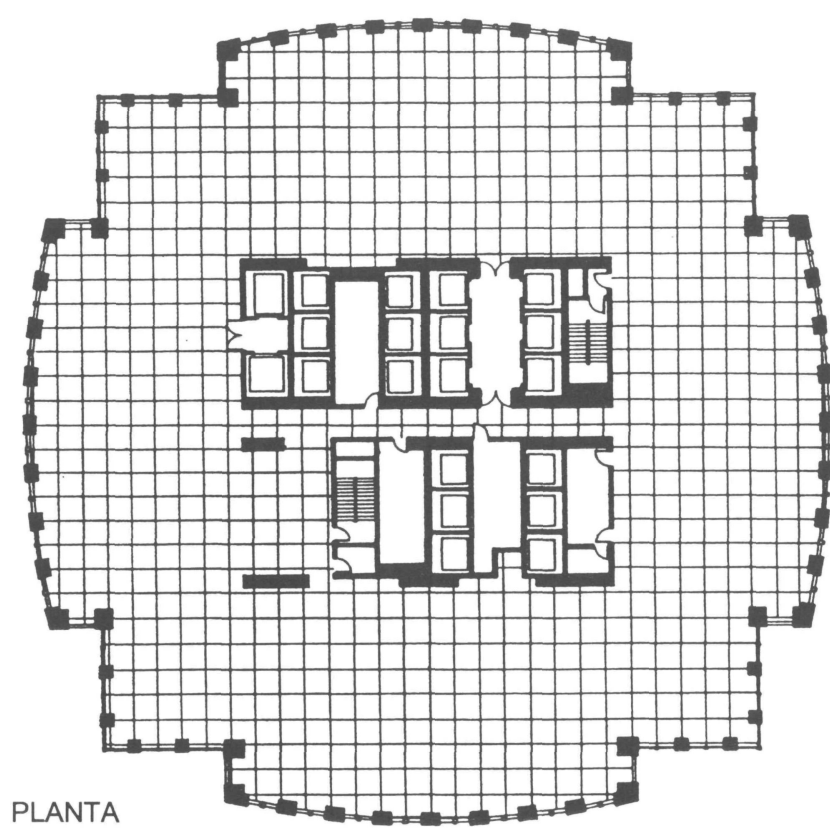

Figura 3

La cimentación tiene una doble tipología, estando formada por una losa de unas dimensiones de $25 \times 28 \times 2,5 \mathrm{~m}$ bajo el núcleo central, y por cajones circulares de entre 1,40 y 1,80 $\mathrm{m}$ de diámetro y de 9 a $30 \mathrm{~m}$ de profundidad bajo los pilares perimetrales.

En este edificio, debido a su altura y distribución de elementos estructurales verticales, se ha estudiado especialmente el acortamiento diferencial de los pilares debido a los esfuerzos elásticos axiles, la retracción y la fluencia del hormigón. Los pilares perimetrales, cuando no se produce una acción importante del viento (y aunque los esfuerzos derivados del mismo los absorba principalmente el núcleo central), reciben un esfuerzo axil menor que los del citado núcleo $\mathrm{y}$, por tanto, tienen un acortamiento inferior. Para reducir este efecto los pilares centrales se ejecutan ligeramente más altos que los perimetrales, hormigonando la losa del forjado con una leve pendiente (en concreto, y a modo de ejemplo, en la planta $40^{\text {a }}$ los pilares centrales $2,50 \mathrm{~cm}$ más altos que los perimetrales). Las vigas radiales se dimensionan teniendo en cuenta el asiento diferencial que se produce entre sus nudos extremos.

La resistencia de proyecto del hormigón empleado es la siguiente:

-Pilares y vigas perimetrales: $55 \mathrm{MPa}$ a $40 \mathrm{MPa}$ (disminuyendo a medida que se asciende en el edificio).

-Vigas centrales y forjado: $35 \mathrm{MPa}$ (hormigón ligero).

\subsection{Bay-Adelaide Center}

Este edificio, situado en Toronto, fue inaugurado en 1990. Tiene 57 plantas y $275 \mathrm{~m}$ de altura. Su planta es rectangular

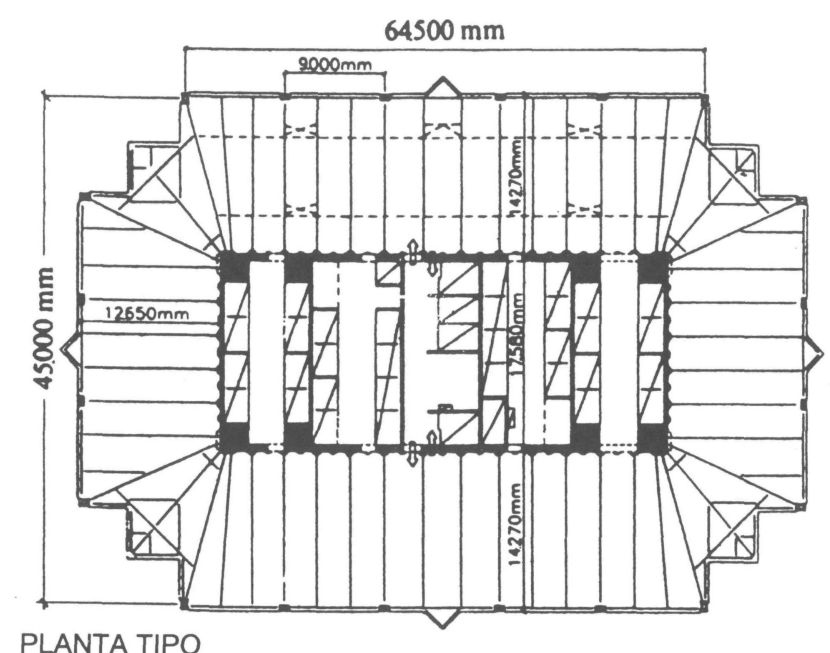

Figura 4

( Figura 4), finalizando con un pináculo piramidal sobre las plantas destinadas a oficinas.

El esquema estructural está formado por un núcleo central de hormigón y un pórtico perimetral metálico, estando constituido el forjado por una sección mixta (losa de hormigón sobre vigas metálicas).

Los muros longitudinales tienen un espesor de $0,65 \mathrm{~m}$, los finales (alas) de 0,30 m y los internos de 0,25 m.

El hormigón tiene una resistencia de proyecto máxima de $85 \mathrm{MPa}$, mientras el límite elástico del acero empleado en la estructura metálica es de $450 \mathrm{MPa}$.

Si en un edificio con núcleo central y pilares perimetrales de hormigón, debido a los esfuerzos axiles, a la retracción y a la fluencia, se presentan diferencias en el acortamiento de los elementos estructurales verticales, en éste, con núcleo de hormigón y soportes metálicos, el problema puede agravarse. La citada diferencia de acortamiento alcanza el valor de $85 \mathrm{~mm}$. Para reducir el efecto negativo que el mismo puede tener sobre el edificio a medio y largo plazo se adoptó como solución el montaje de los pilares a una cota ligeramente distinta que el nivel del núcleo central en la misma planta.

\subsection{Edificio de la Banca de la Agricultura y la Industria}

Este edificio, situado en Perth (Australia) y construido en el primer lustro de los años 90 , tiene $207 \mathrm{~m}$ de altura y 48 plantas. Se ha incluido dentro del área norteamericana por la influencia de la cultura anglosajona en este país-continente.

Su esquema estructural, como se puede apreciar en la figura 5, siguiendo la planta triangular del edificio, dispone un núcleo rígido formando una " $L$ " en la esquina correspon- 

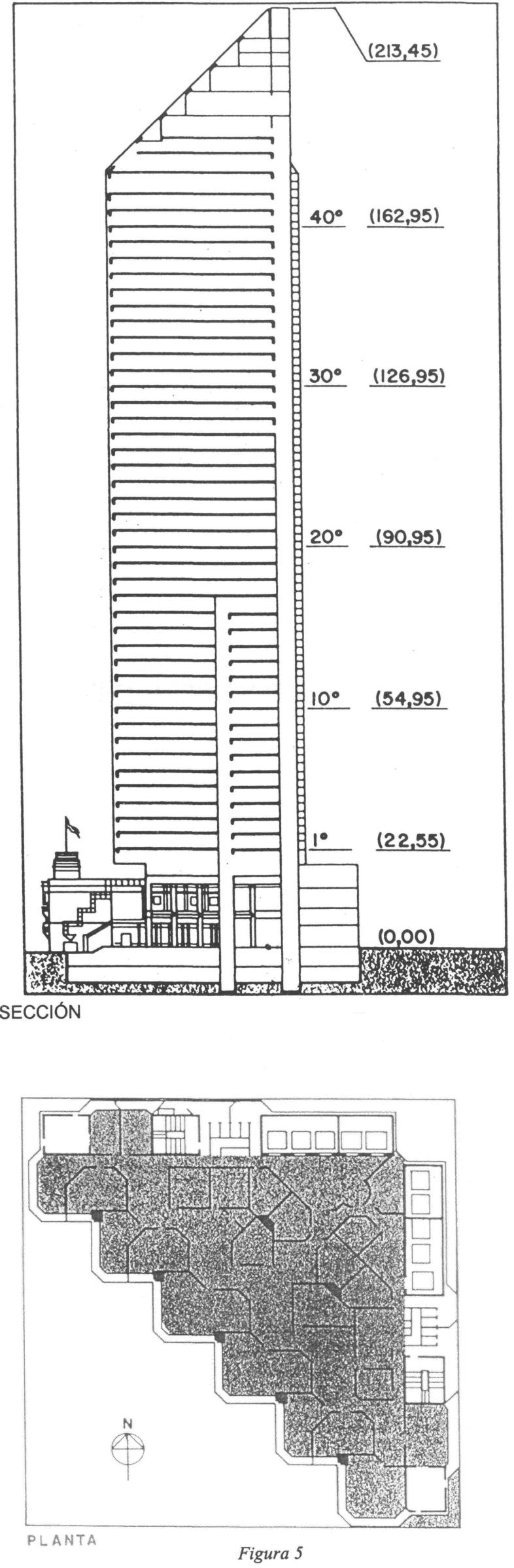

diente al ángulo recto, una alineación de pilares en la fachada situada en la hipotenusa y dos soportes interiores, todo ello de hormigón.

Los pilares de la fachada, de sección cuadrada de 1,30,1,20 y 1,14 m de lado en las plantas inferiores y circular (anular) de diámetro $0,50 \mathrm{~m}$ por encima de la planta $33^{\mathrm{a}}$, están constituidos por hormigón, con resistencia de proyecto entre $65 \mathrm{MPa}$ en las plantas inferiores y $25 \mathrm{MPa}$ en las superiores.

El núcleo central, por lo que respecta a la resistencia de proyecto del hormigón, sigue una evolución similar, variando entre 40 y $25 \mathrm{MPa}$. El espesor de los muros decrece entre 0,45 y $0,25 \mathrm{~m}$ según se asciende en el edificio.

La cimentación está constituida por pilotes de $1,50 \mathrm{~m}$ de diámetro, con $30 \mathrm{~m}$ de longitud y empotrados $2,90 \mathrm{~m}$ en el terreno que ha de recibir las cargas.

\subsection{Edificio Trianon}

El número de plantas de este edificio es de 48 sobre rasante y 4 sótanos, con una altura de $186 \mathrm{~m}$ sobre aquélla y 19,61 m bajo la misma. Su planta es, básicamente, triangular, con cierta irregularidad en los vértices. Se encuentra en Frankfurt y su proceso de proyecto y construcción se desarrolló durante los últimos años de la década de los 80 y primeros de la de los 90 (Foto 2).

Su esquema estructural, como puede apreciarse en la figura 6, está formado por un enrejado de hormigón en la fachada, tres núcleos exteriores en los vértices, tres núcleos triangulares interiores y tres pilares principales, también interiores.

El enrejado o pórtico de fachada, que se puede observar en la foto 3 durante la construcción del edificio, está formado por pilares de $0,54 \mathrm{~m}$ de ancho (dirección paralela a la fachada), con una distancia entre caras de $1,40 \mathrm{~m}$, siendo su fondo (dirección normal a la fachada) de 0,33 a 0,53 m según la altura del mismo. Las vigas que unen estos pilares tienen $0,30 \mathrm{~m}$ de ancho y un canto entre 0,50 y $1,11 \mathrm{~m}$.

El forjado está constituido por una losa de hormigón de $0,15 \mathrm{~m}$ de espesor sobre unas vigas de $1,00 \mathrm{~m}$ de ancho y $0,27 \mathrm{~m}$ de canto $(0,15+0,12)$, separadas entre sí entre 4,20 y $5,60 \mathrm{~m}$ y con una luz de $8,70 \mathrm{~m}$.

La cimentación del bloque principal del edificio (existe una zona aneja con una altura sensiblemente menor), la forma una losa de 6,00 m de canto. La mencionada zona aneja se apoya sobre una losa de $1,00 \mathrm{~m}$ de canto soportada por pilotes. Ejecutadas ambas cimentaciones de forma independiente, transcurrido un tiempo que permitiera que se produjeran los primeros asientos, se unieron ambas mediante otra losa. 


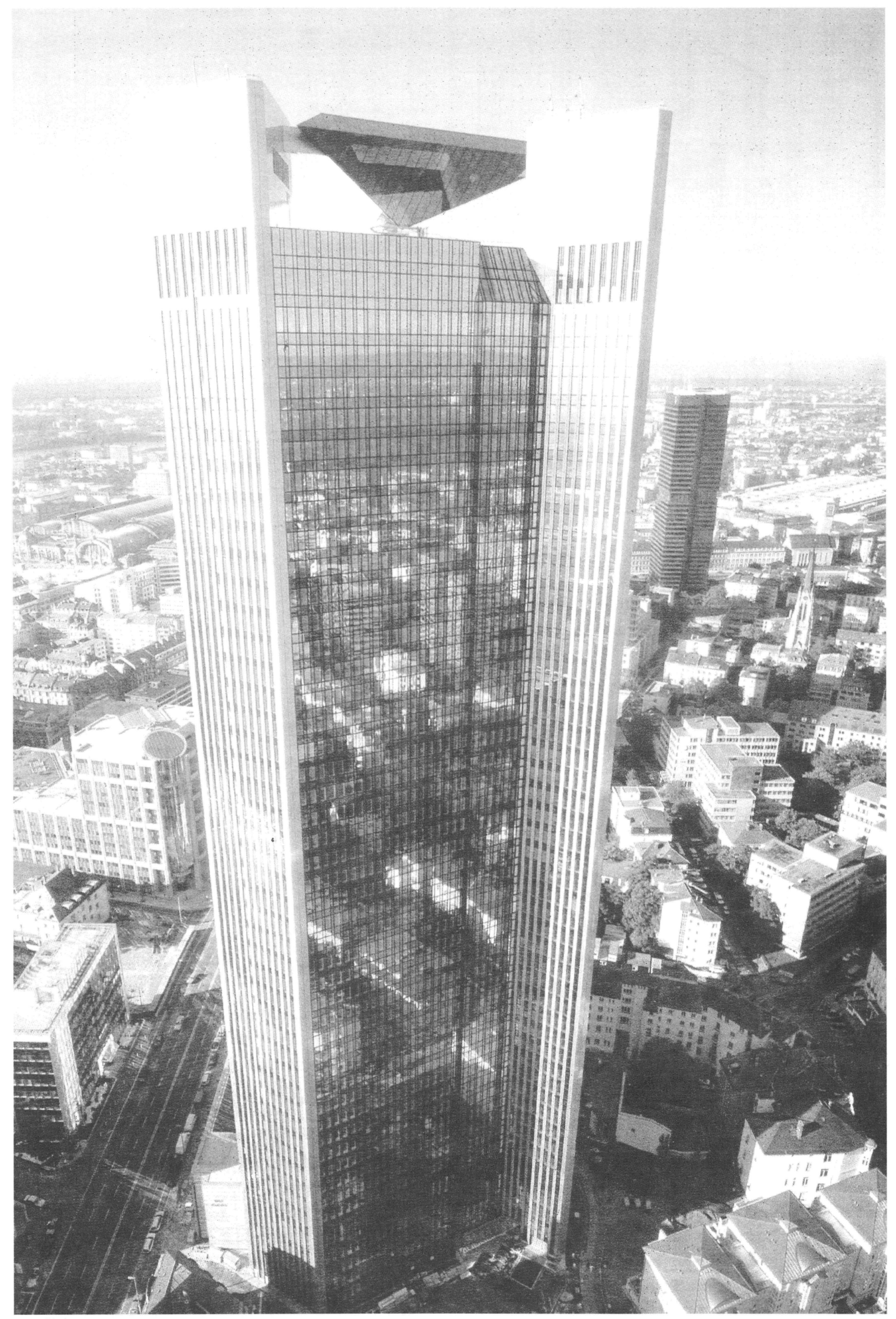

Foto 2 

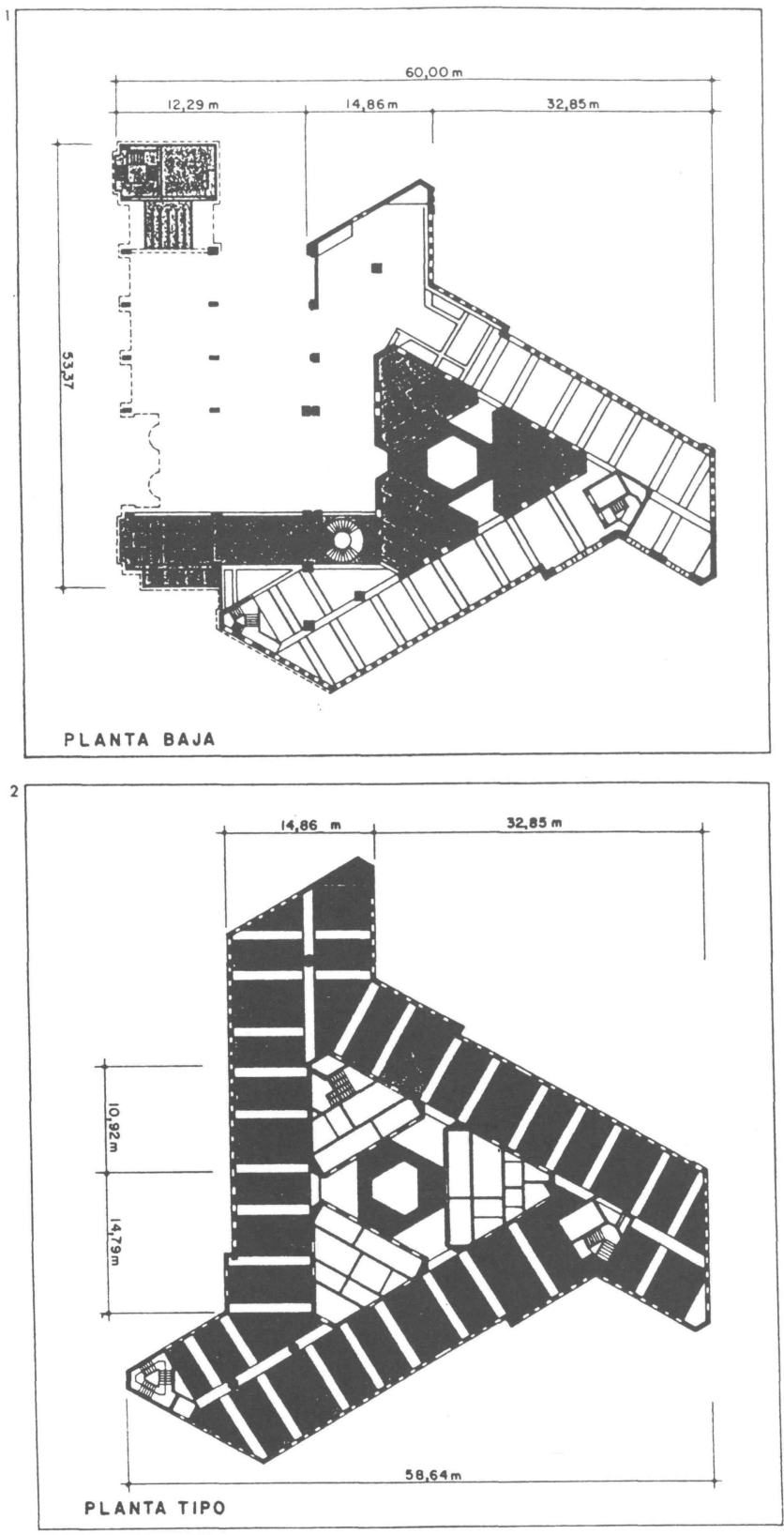

Figura 6

El hormigón empleado responde a los tipos B45 (45 MPa de resistencia de proyecto) en las plantas situadas bajo el enrejado de fachada, y B35 en el resto de la estructura. En los pilares y muros más cargados, en las plantas inferiores, como se aprecia en la figura 7, se empleó hormigón tipo B85, siendo la primera ocasión en que se construía con este hormigón en Alemania.

En la figura 8 se recogen, de forma muy gráfica, los resultados obtenidos del cálculo de un soporte tipo con una sección de 1,00x1,00 m y hormigón tipo B85, otro de la misma sección, pero hormigón tipo B45 y un tercero con el mismo hormigón tipo B85 reduciendo la sección. En la misma se puede apreciar la reducción en la armadura o la disminución de la sección de hormigón que se obtienen con el empleo de este hormigón de alta resistencia.

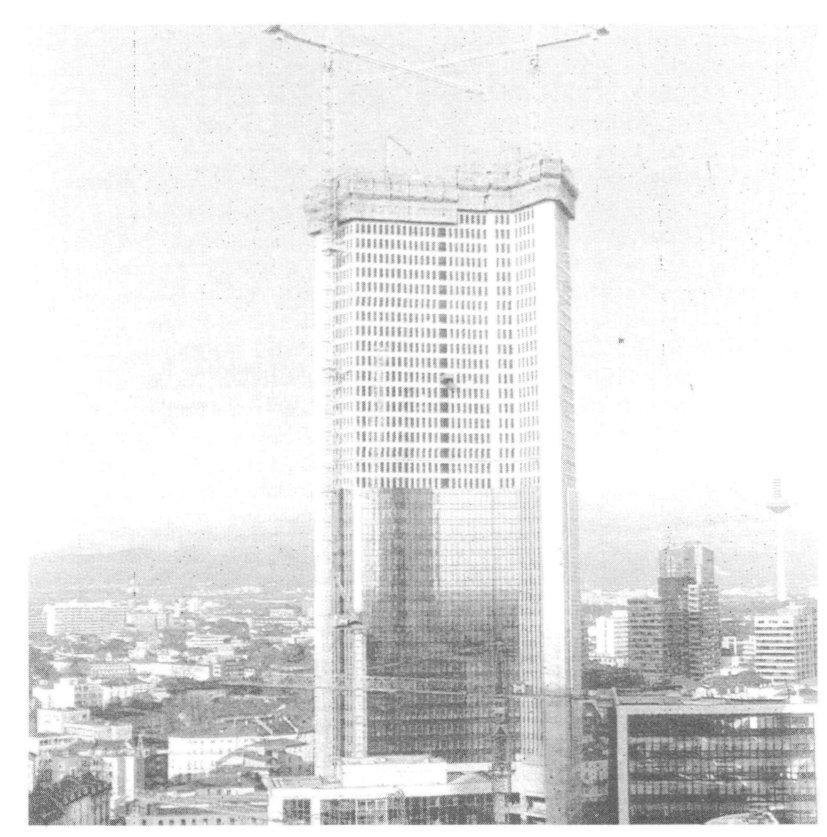

Foto 3

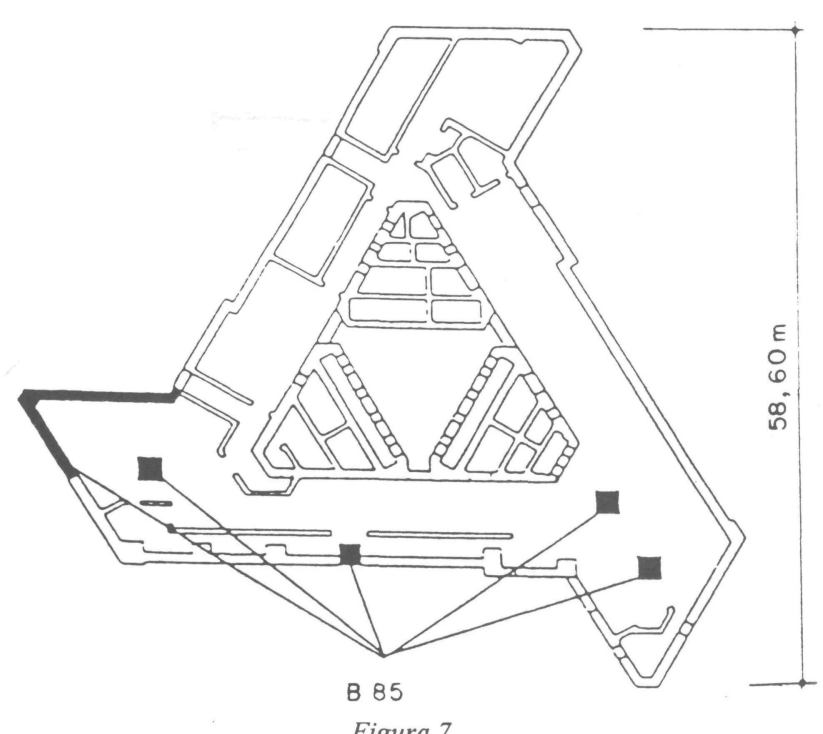

Figura 7

\subsection{Japan Center}

Este edificio, terminado de construir en 1996 y situado en Frankfurt, tiene 32 plantas ( 28 de ellas sobre rasante y 4 sótanos) y una altura de $115 \mathrm{~m}$. Su planta es un cuadrado de $37 \mathrm{~m}$ de lado (Figura 9).

El esquema estructural responde al sistema de "tubo en tubo", formado por un núcleo central y un pórtico tridimensional perimetral, ambos de hormigón. En esta ocasión cada uno de ellos dimensionado para absorber el $50 \%$ de las acciones horizontales de viento.

Los pilares y las vigas de la corona perimetral están ejecutados con un hormigón de tipo $\mathrm{C} 105$ (resistencia de proyecto $105 \mathrm{MPa}$ ) en las 12 plantas inferiores, siendo las dimen- 


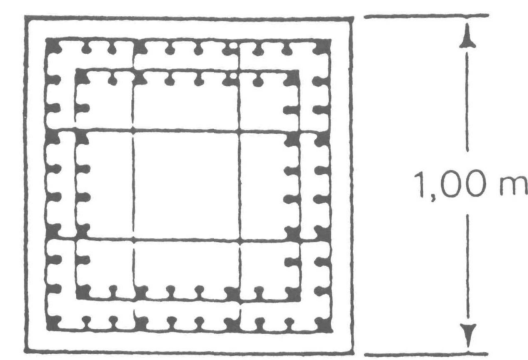

$B 45$
$-1,00 \mathrm{~m} \rightarrow \mid$

$\max . \mathrm{N}=21 \mathrm{MN}$

$\mu=4,0 \%$

$64 \varnothing 28$

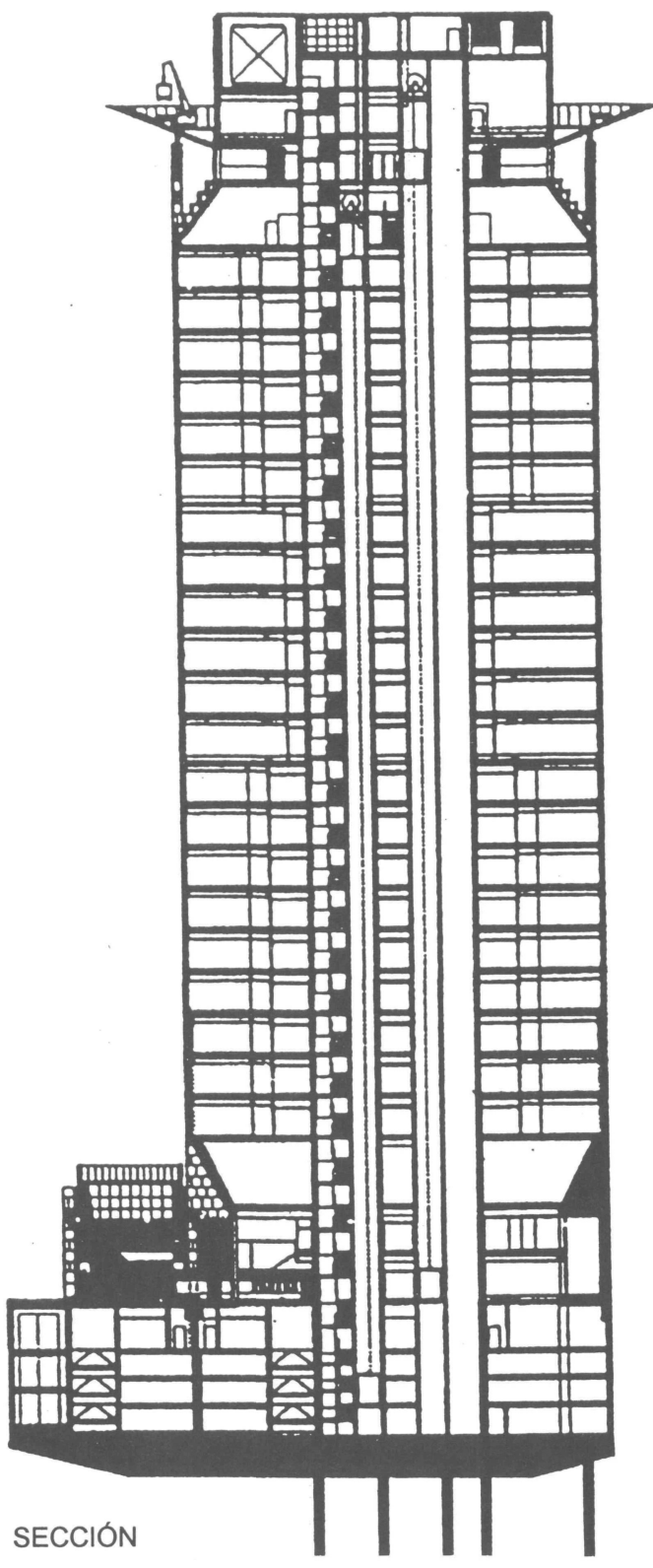

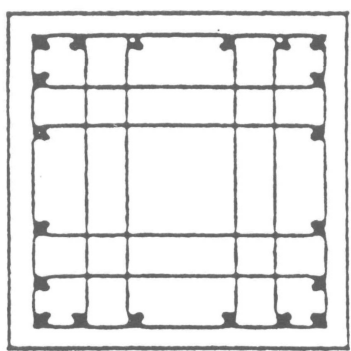

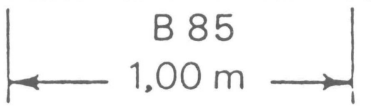

$$
\begin{gathered}
\max . N=21 \mathrm{MN} \\
\mu=1,23 \% \\
20 \varnothing 28
\end{gathered}
$$
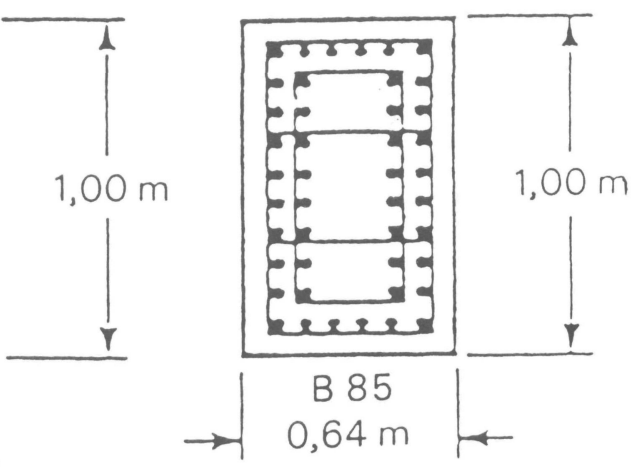

$$
\begin{gathered}
\max . N=21 \mathrm{MN} \\
\mu=4,0 \% \\
40 \varnothing 28
\end{gathered}
$$

Figura 8

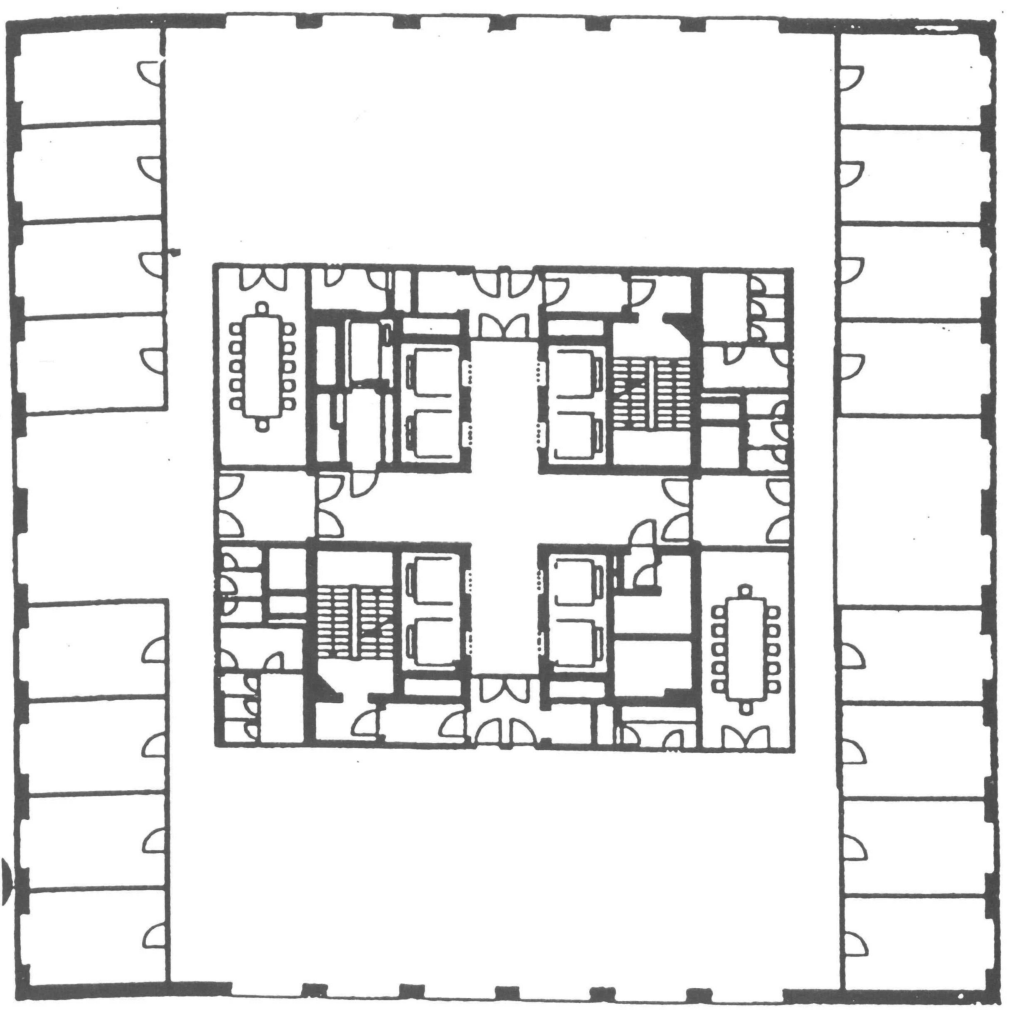

PLANTA TIPO

Figura 9 
siones de la sección de aquéllos de 0,35x0,72 m. En el predimensionado efectuado con hormigón tipo $\mathrm{C} 45$ la sección obtenida era de 0,55x0,72 m (incrementándose además notablemente la armadura), siendo una de las principales razones del uso del hormigón de alta resistencia obtener la máxima superficie útil en el edificio.

El forjado está constituido por una losa de $0,35 \mathrm{~m}$ de canto y $10,80 \mathrm{~m}$ de luz libre.

La cimentación, directa, se ejecuta mediante una losa de 3,50 $\mathrm{m}$ de espesor apoyada sobre 25 pilotes de $1,30 \mathrm{~m}$ de diámetro y $22 \mathrm{~m}$ de profundidad.

\subsection{Pacific Tower}

Este edificio, construido en los más recientes años 90, se encuentra situado en el barrio de La Défense, en París (Foto 4). Tiene 27 plantas sobre rasante y 2 sótanos. Su distribución en planta, tanto en sótanos como en las 7 plantas superiores, responde a un casquete circular, mientras que la planta baja y las 19 plantas tipo intermedias se encuentran dispuestas según dos sectores circulares.

Su esquema estructural está formado, para cada uno de los dos sectores citados, por un núcleo central y un tubo de hormigón perimetral (Figura 10), cuyas únicas aberturas son las ventanas de las plantas intermedias y superiores y unos pórticos en las inferiores.

El forjado está constituido por una losa de hormigón que se encuentra unida a los soportes a través de perfiles metálicos.

El tipo de hormigón empleado es el B30 (30 MPa de resistencia a compresión) en forjados, y B45 y B60 en los soportes verticales, disminuyendo su resistencia al ascender en altura el edificio. Para este último la resistencia a compresión pedida en proyecto a los 28 días era de $72 \mathrm{MPa}$.

\subsection{New Century Hotel}

Finalizada su construcción en 1989, y constituido por dos torres de 37 y 17 plantas sobre otras 3 plantas comunes sobre rasante a modo de "podium" y 2 sótanos, este edificio se encuentra en Beijing (China). La torre de mayor altura tiene una planta triangular (Figura 11), con prolongación de cada lado en uno de sus extremos al llegar al vértice.

El esquema estructural de esta torre está formado por un núcleo central triangular, unos muros en los vértices y unos pórticos en las fachadas, todos ellos de hormigón, encontrándose los pilares de éstas separados 7,60 m.

Inicialmente, la estructura del edificio se planteó con un hormigón tipo C40 (40 MPa de resistencia a compresión). Los pilares de las plantas inferiores tenían una sección de 1,27x1,27 m. Posteriormente, se proyectaron con hormigón tipo $\mathrm{C} 60$ y con una sección mixta formada por un cuadrado de $0,90 \times 0,90 \mathrm{~m}$ de hormigón con un tubo armado metálico interior de 450x450 mm (Figura 12). Este cambio supuso un aumento en la superficie útil de $129,5 \mathrm{~m}^{2}$.

En la figura 13 puede apreciarse, de forma esquemática, la sección de los pilares y el tipo de hormigón empleado en cada una de las plantas, variando entre 0,90x0,90 y 0,80x0,80 m, y C60 y C30, respectivamente, disminuyendo la resistencia a compresión del hormigón a medida que se asciende en el edificio.

\subsection{Central Plaza}

Edificio de 78 plantas y $374 \mathrm{~m}$ de altura (incluyendo el mástil). Se encuentra en la ciudad de Hong Kong y su construcción finalizó en 1992. Su planta ès triangular y dispone de 3 plantas sótano.

El esquema estructural está constituido por un núcleo central triangular formado por tres conjuntos de muros, un pórtico perimetral en la fachada (que en las plantas bajas y altas pierde alternativamente uno de cada dos pilares), y un gran soporte circular interior (Figura 14).

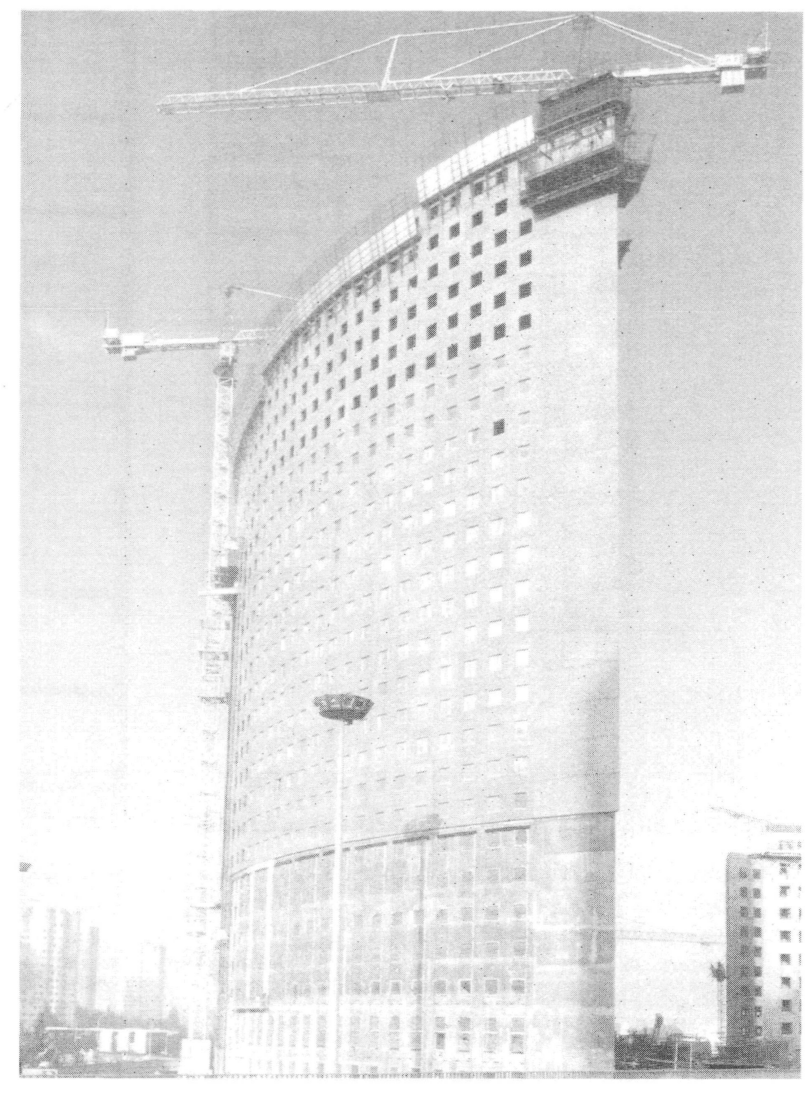

Foto 4 


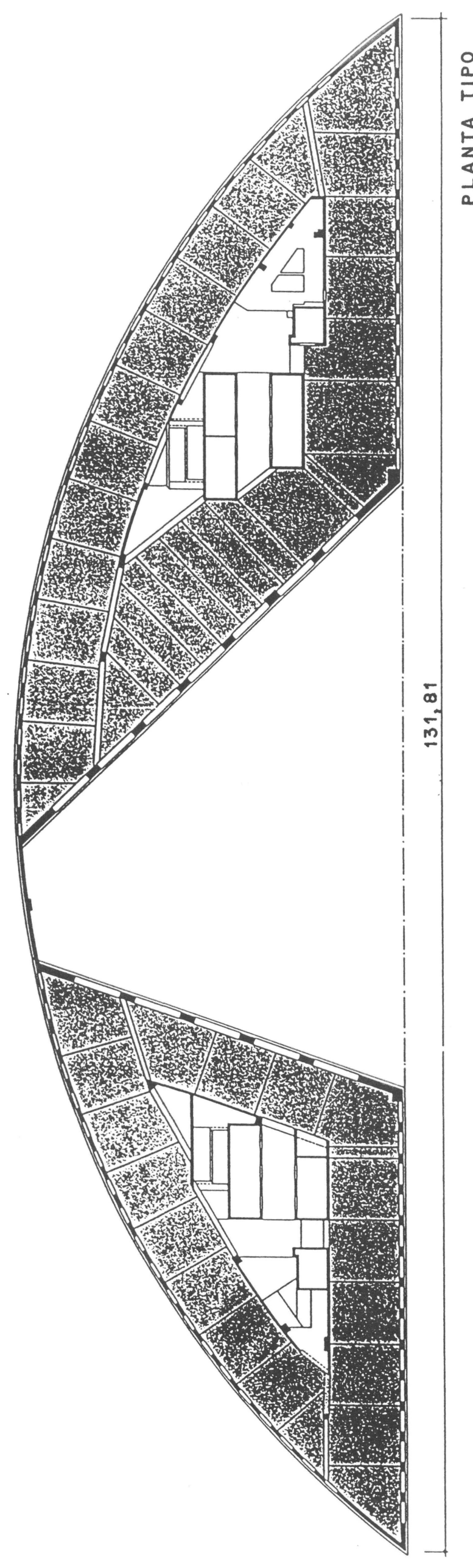

(c) Consejo Superior de Investigaciones Científicas Licencia Creative Commons 3.0 España (by-nc)

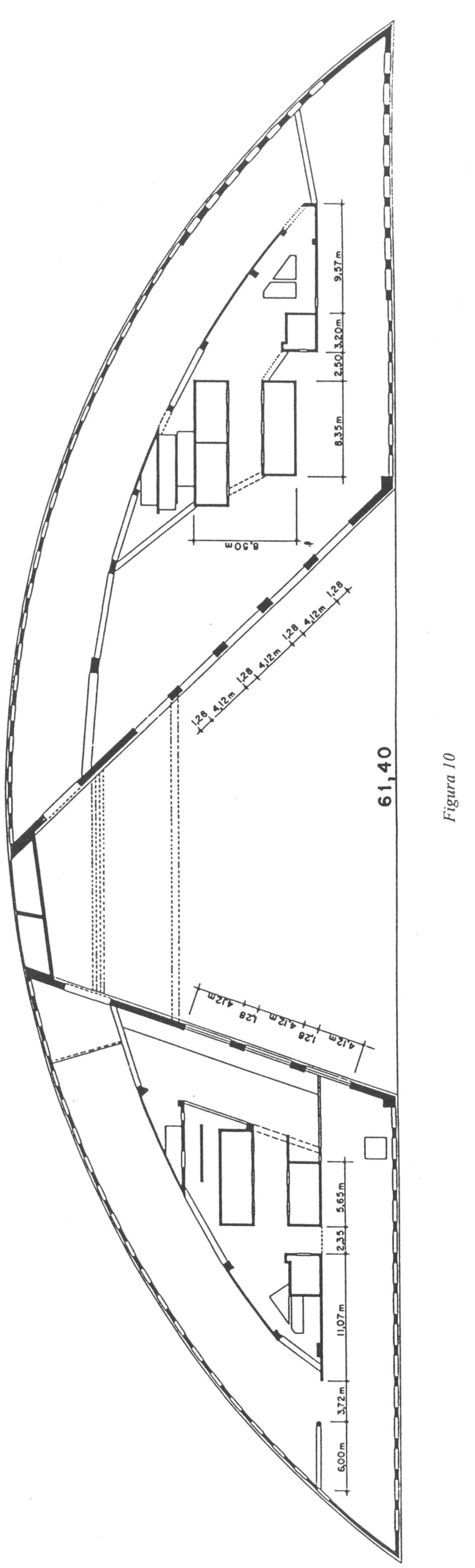

http://informesdelaconstruccion.revistas.csic.es 

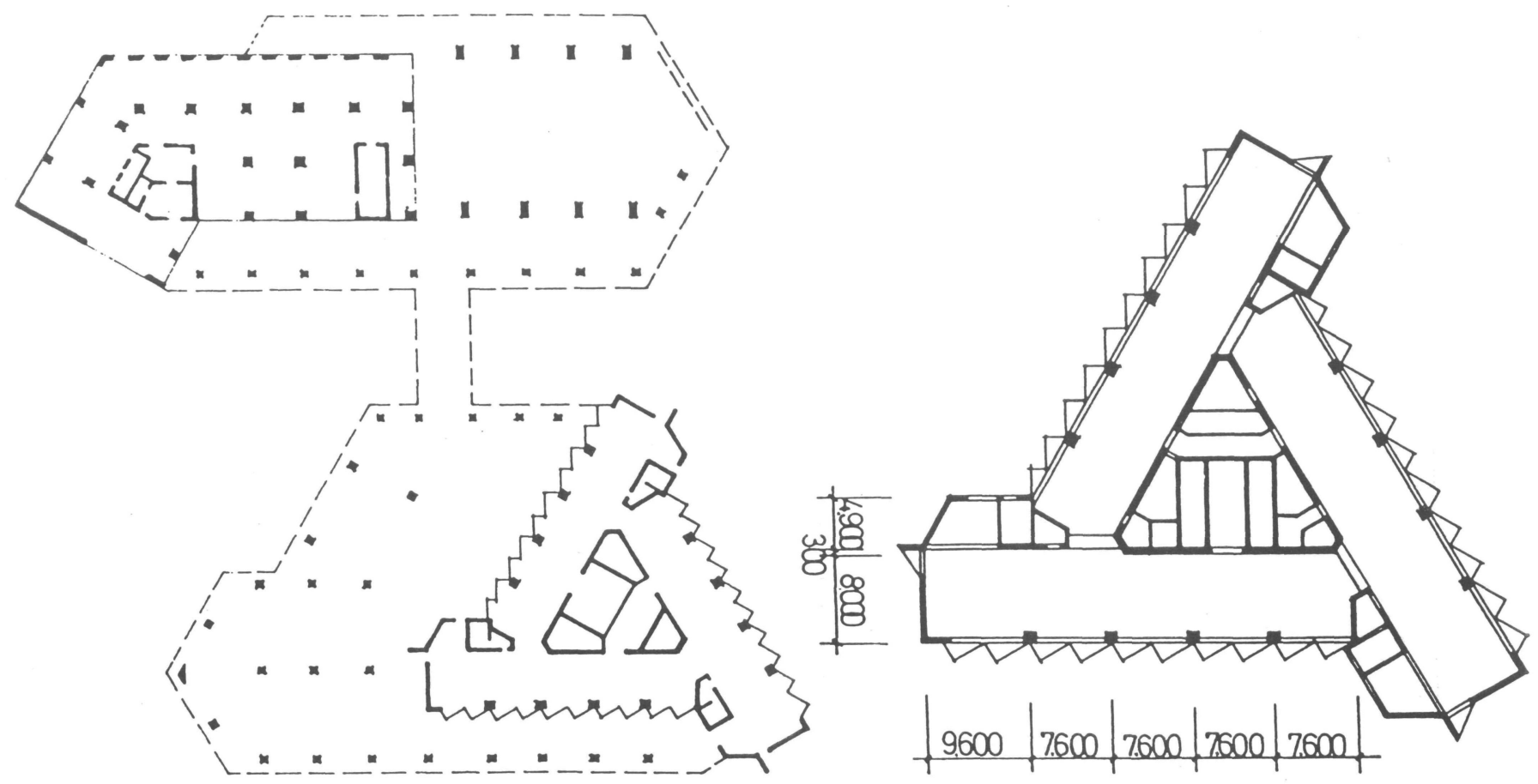

PLANTA DEL "PODIUM"

PLANTA TIPO

Figura 11
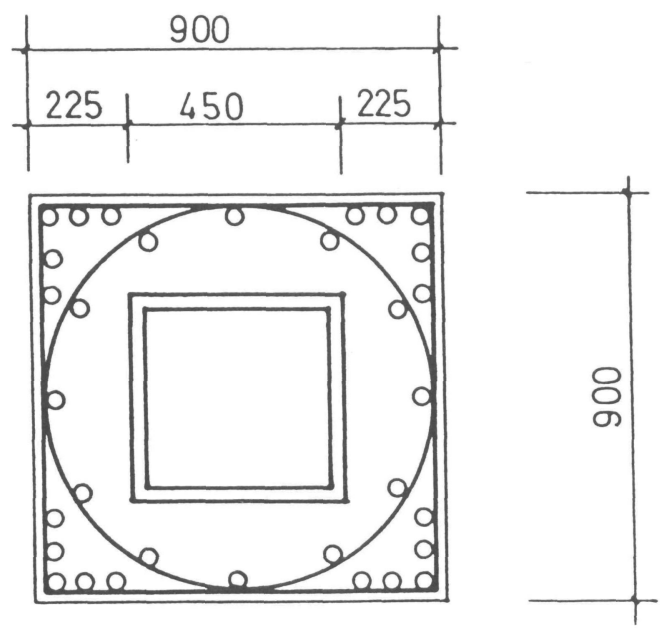

SECCIÓN TIPO DE SOPORTE COMPUESTO

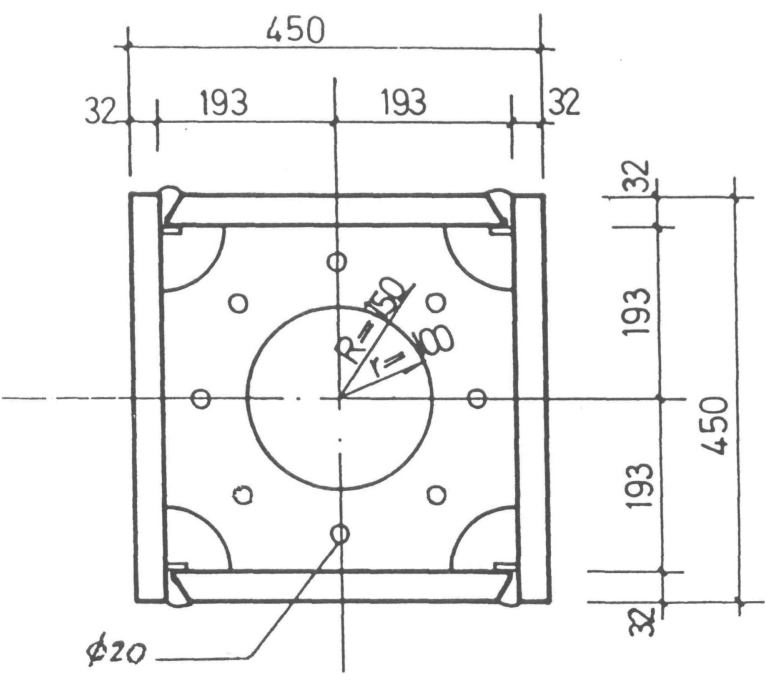

SECCIÓNDEL TUBO METÁLICO INTERIOR DEL SOPORTE DE HORMIGÓN 


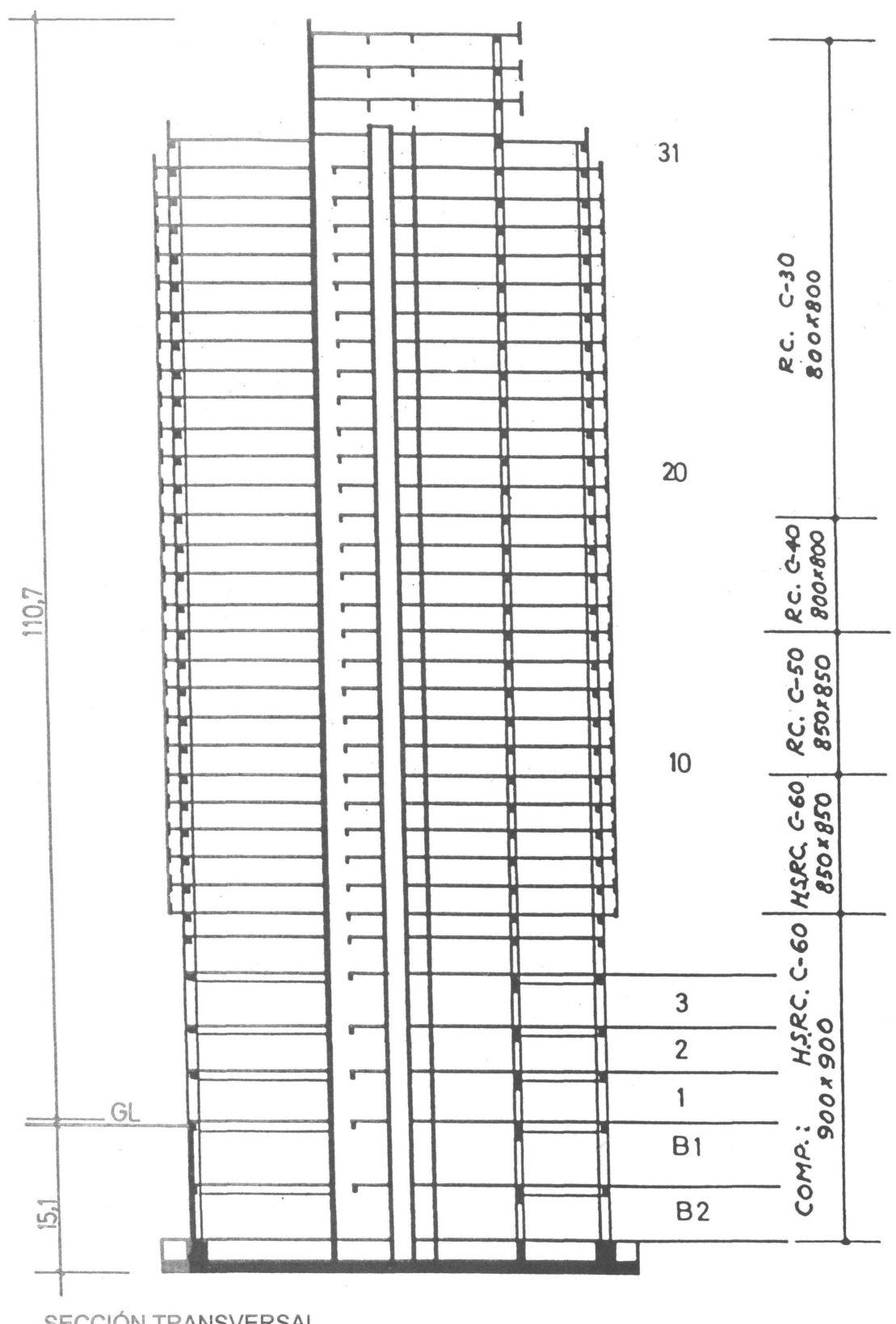

Figura 13

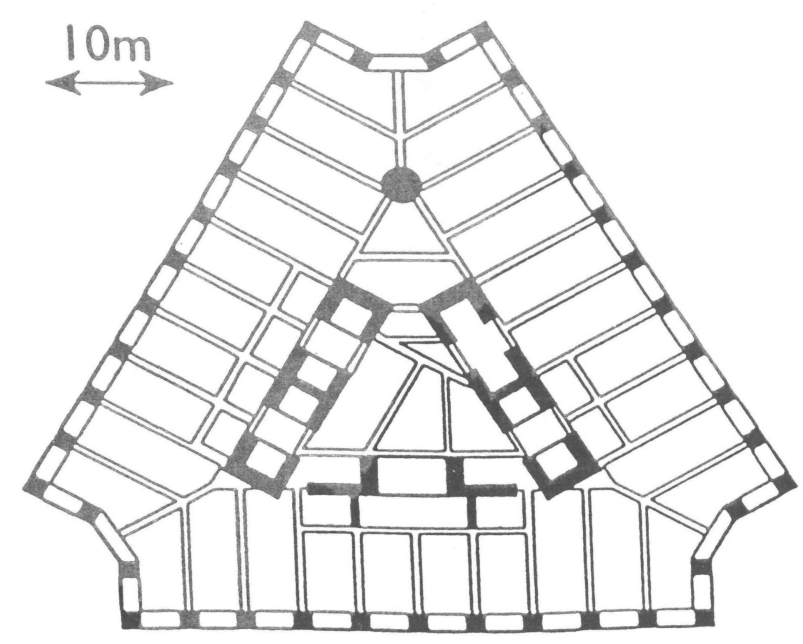

PLANTA TIPO

Figura 14
El hormigón empleado en los soportes tiene una resistencia a compresión de $60 \mathrm{MPa}$. El proyecto, inicialmente, estaba desarrollado con el pórtico perimetral constituido por elementos metálicos, ya que la normativa vigente en la ciudad sólo permitía la utilización de hormigón de $40 \mathrm{MPa}\left(40 \mathrm{~N} / \mathrm{mm}^{2}\right.$ de resistencia a compresión en probeta cúbica), lo que imposibilitaba esta solución. Posteriormente, tras el desarrollo de un minucioso estudio de materiales de la zona y de dosificaciones, se obtuvo el permiso para el uso del citado material estructural.

\subsection{Sky Central Plaza}

Este edificio, situado en Guangzhou (China), tiene 80 plantas y $322 \mathrm{~m}$ de altura de estructura principal (Foto 5) y $352 \mathrm{~m}$ el punto más elevado. Su construcción ha finalizado en 1997, siendo en su momento el más alto del mundo con 


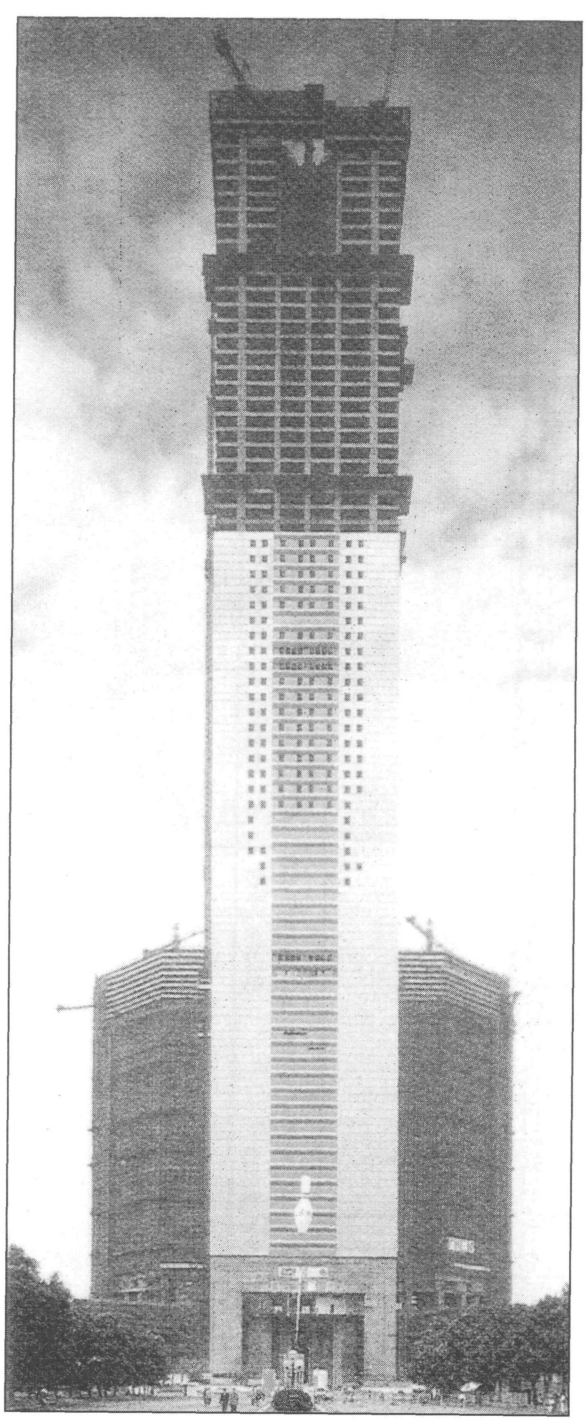

Foto 5

estructura de hormigón. Junto al mismo se elevan otras dos torres de 38 plantas cada una, sumando el conjunto una superficie total de unos $300.000 \mathrm{~m}^{2}$.

El esquema estructural responde a la tipología de "tubo en tubo", constituido por un núcleo central y un pórtico perimetral exterior, ambos de hormigón. El núcleo está formado por muros cuyo espesor en las plantas bajas es de 0,60 y $1,10 \mathrm{~m}$.

El pórtico perimetral de fachadas dispone de pilares de $2,50 \times 2,50 \mathrm{~m}$ en las esquinas y de $1,50 \times 1,50 \mathrm{~m}$ en el resto, siendo su separación de 7,50 y 9,50 m. Las vigas perimetrales en las plantas tipo tienen unas dimensiones de 0,80x1,05 m, siendo las vigas de apeo de $1,50 \times 8,50 \mathrm{~m}$ en la planta tercera. En esta misma planta una losa de $1,00 \mathrm{~m}$ de canto transfiere al núcleo las acciones y esfuerzos cortantes debidos al viento y al sismo. El forjado, en las 68 plantas tipo está constituido, fundamentalmente, por una losa de $0,125 \mathrm{~m}$ de espesor.
El hormigón empleado en los elementos estructurales verticales tiene una resistencia a compresión de $60 \mathrm{MPa}$.

\subsection{Jin Mao Tower}

Este edificio, con 88 plantas y $421 \mathrm{~m}$ de altura, se encuentra situado en la ciudad de Shanghai, estando prevista la finalización de su construcción para el presente año de 1998. Su uso será de oficinas en las 50 plantas inferiores y

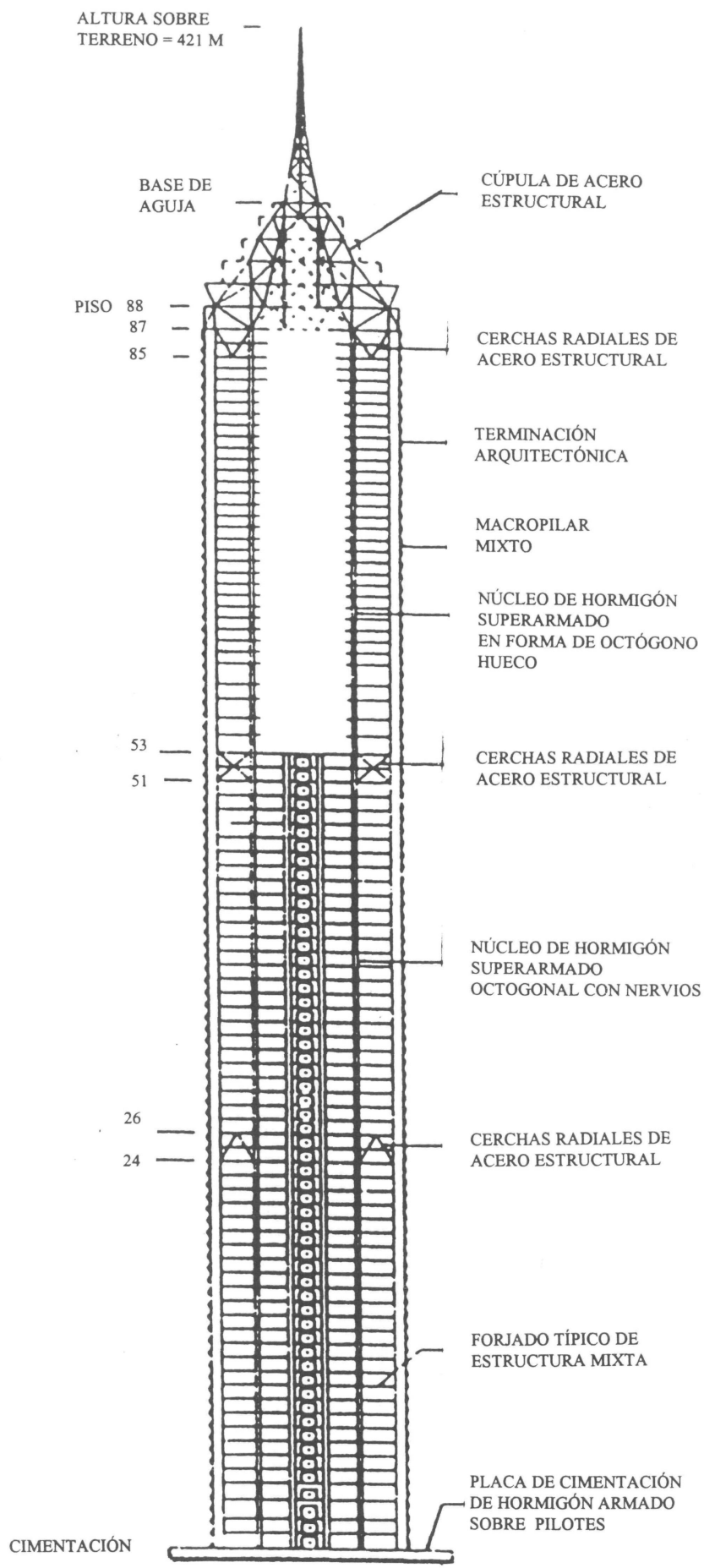

SISTEMA ESTRUCTURAL

Figura 15 
de hotel en las 38 superiores, siendo la superficie total de $280.000 \mathrm{~m}^{2}$. Dispone de un atrio en la zona central a lo largo de toda la altura que ocupa el hotel, $206 \mathrm{~m}$ (Figura 15).

La solución estructural mixta adoptada combina las ventajas del hormigón (masa, resistencia, rigidez y amortiguamiento) con las del acero (resistencia, rapidez de construcción, capacidad para luces grandes y ligereza). El esquema estructural está formado, básicamente, por un núcleo central octogonal de hormigón armado y por 16 pilares situados en las fachadas y con una distribución simétrica.

El núcleo central, de $27 \mathrm{~m}$ de ancho total, se encuentra atravesado por cuatro diafragmas ortogonales dos a dos hasta la planta $53^{\mathrm{a}}$ (Figura 16). Los muros perimetrales

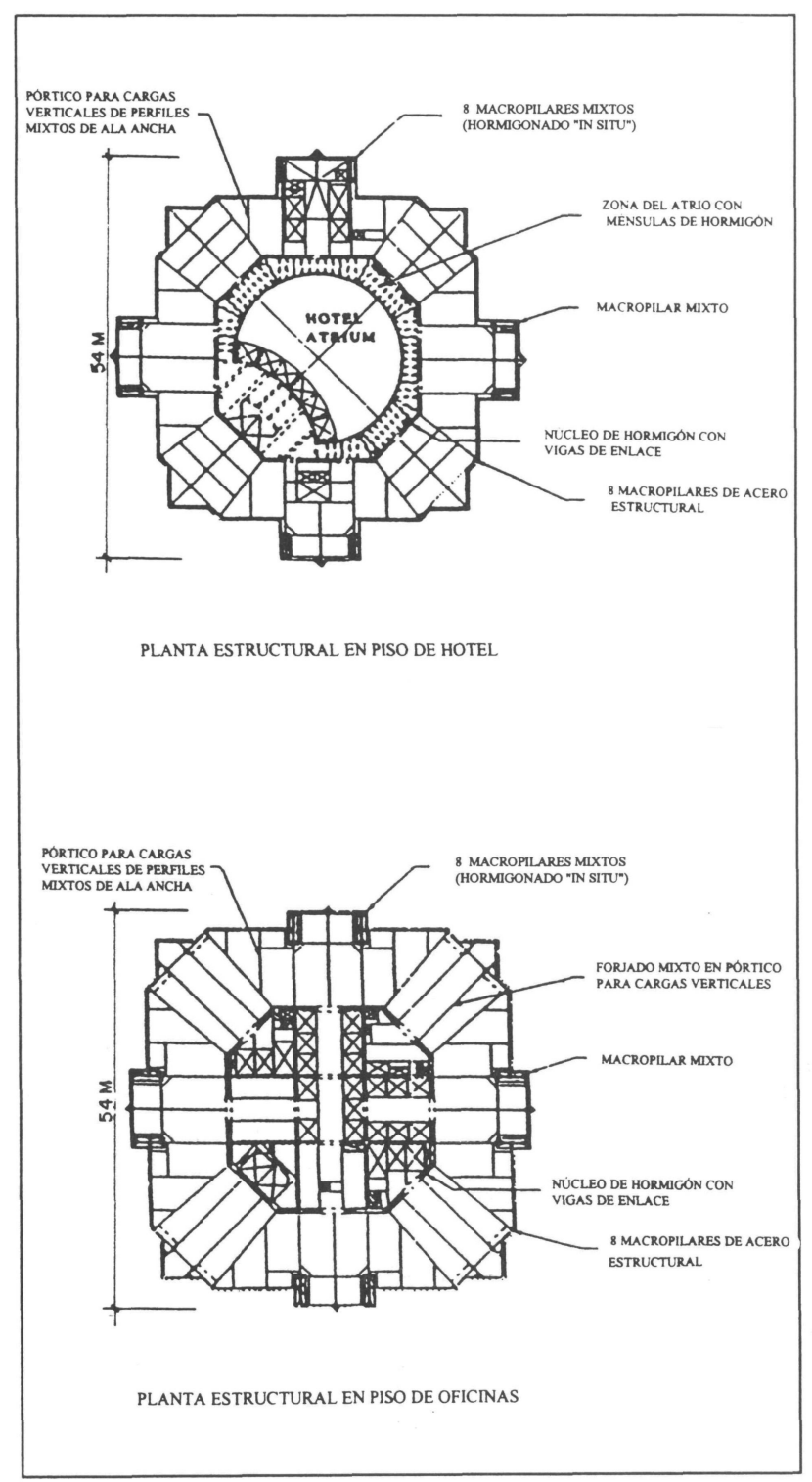

Figura 16 tienen un espesor de $0,85 \mathrm{~m}$ en las plantas inferiores, disminuyendo hasta alcanzar los $0,45 \mathrm{~m}$ en la planta $87^{\mathrm{a}}$. Los interiores y normales entre sí por pares tienen un espesor constante de $0,45 \mathrm{~m}$ en sus 53 plantas.

Los pilares perimetrales se encuentran divididos en 8 mixtos y 8 metálicos. Los soportes mixtos nacen con unas dimensiones de 1,50x5,00 m en la cimentación y finalizan con $1,00 \times 3,50 \mathrm{~m}$ en la planta $87^{\mathrm{a}}$.

En tres alturas del edificio, y ocupando cada una dos plantas (24 a 26, 51 a 53 y 85 hasta cubierta), existe un conjunto de cerchas que unen ambos sistemas estructurales (central y perimetral), permitiendo una transmisión de esfuerzos más coherente (Figura 17).
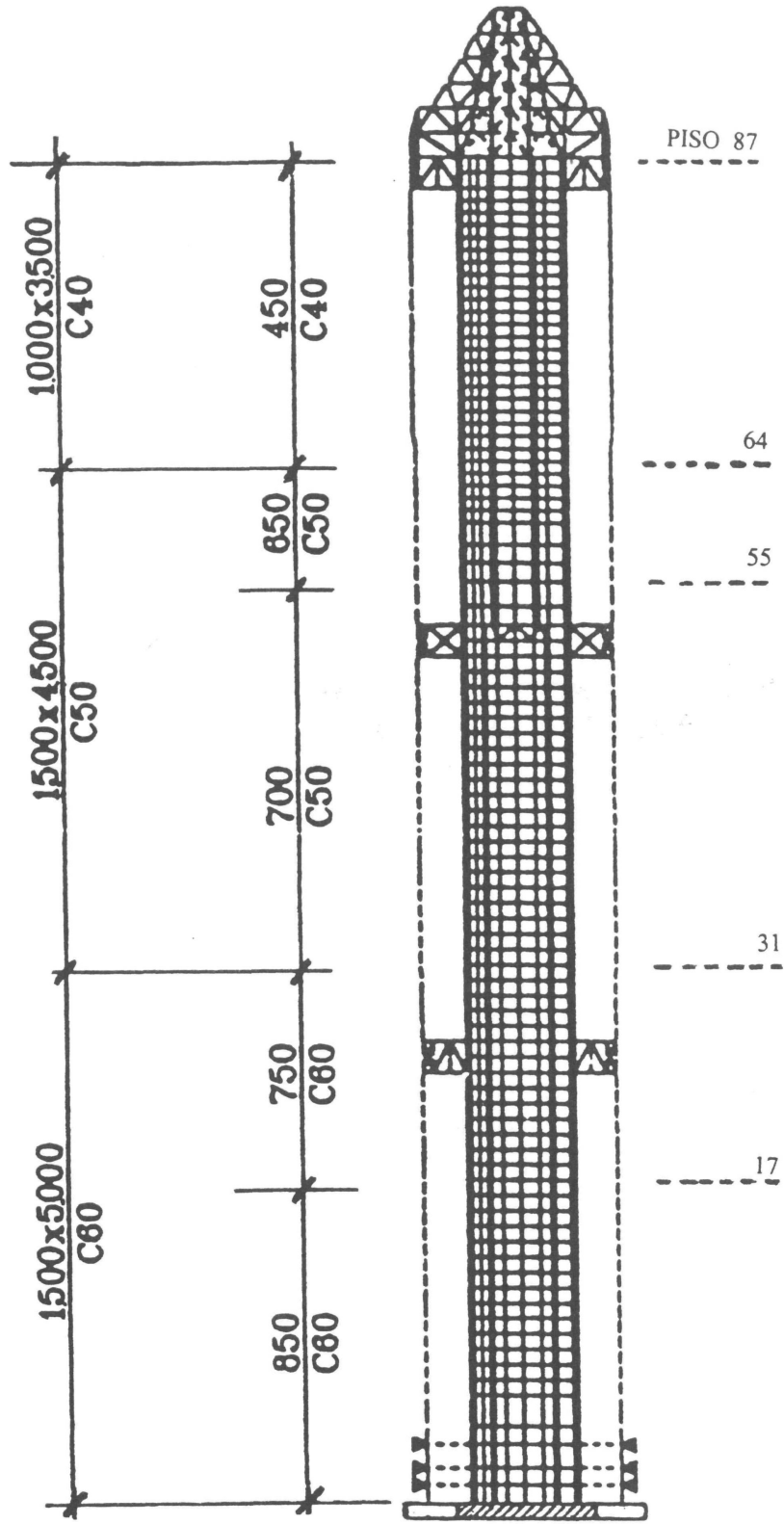

TIPO DE HORMIGÓN Y DIMENSIONES DE PILARES Y PANTALLAS 
La cimentación está constituida por una losa de 4,00 $\mathrm{m}$ de espesor que transmite la carga al terreno a través de 429 pilotes.

Como se puede apreciar en la mencionada figura 17, el tipo de hormigón puesto en obra, tanto en el núcleo central como en los soportes mixtos exteriores, varía con la altura del edificio entre el C60 hasta la planta $31^{\mathrm{a}}$, el C50 entre ésta y la $64^{\mathrm{a}}$, y el C40 hasta la $87^{\mathrm{a}}$. En la misma se puede seguir también la evolución del espesor de los muros del núcleo central y de la sección de los pilares exteriores.

\subsection{Public Bank Building}

Este edificio de 32 plantas, situado en Johor Bahru(Malaysia) y construido en los primeros años 90 tiene, como puede apreciarse en la figura 18, planta exagonal.

Su esquema estructural está formado por un núcleo situado junto a uno de los lados que constituyen las fachadas, un pilar apantallado en cada uno de los vértices y dos más en la zona central interior. Cada una de las cuatro fachadas principales está recorrida por 3 pilares adicionales entre su apeo en la planta $12^{\mathrm{a}}$ y la cubierta. El sistema de transferencia situado en aquella planta está constituido por 4 vigas de 23,50 m de luz y unas dimensiones (bxh) de 2,15x4,80 m, situadas en los cuatro lados mayores del exágono.

El forjado se encuentra proyectado, básicamente, con 6 vigas principales de hormigón pretensado (postesadas), de las que 4 tienen $18,40 \mathrm{~m}$ de luz, sobre las que se sitúa una losa de $0,15 \mathrm{~m}$ de espesor.

El hormigón empleado en los pilares ha de tener una resistencia a compresión de $65 \mathrm{MPa}$, siendo la primera vez que se usó este tipo de hormigón en Malaysia.

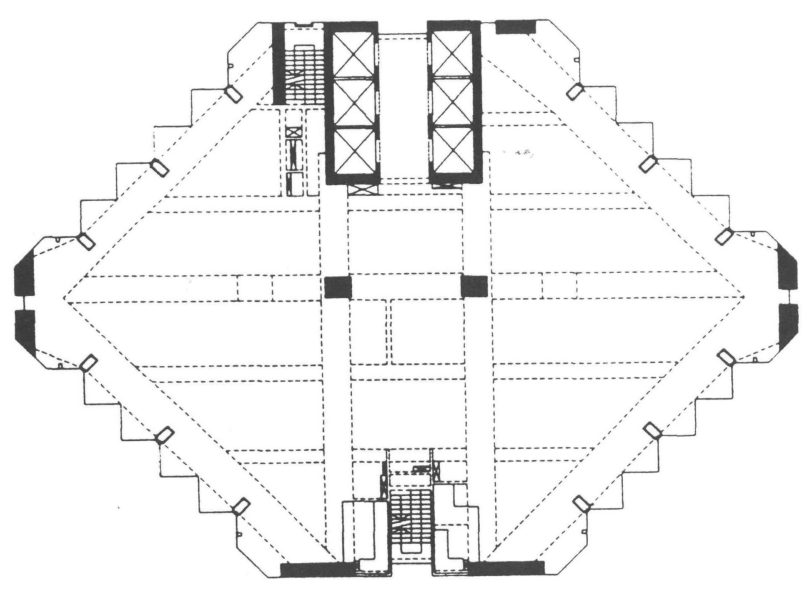

PLANTA DE TRANSFERENCIA

Figura 18

\subsection{Petronas Towers}

Este conjunto de dos torres, de 88 plantas cada una ( 82 sobre rasante y 6 plantas sótano), cuyo final de construcción está previsto para el presente año de 1998, se encuentra situado en Kuala Lumpur, Malaysia. Con sus 450 m, constituyen el edificio más alto del mundo. Cada torre tiene planta circular, encontrándose adosados a ellas sendos edificios de 38 plantas (Foto 6).

Ante la envergadura del edificio que se iba a proyectar, inicialmente se plantearon cinco alternativas estructurales:

-Núcleo y sistema cilíndrico exterior (pórtico de fachada) metálicos.

-Núcleo de hormigón y pórtico perimetral metálico.

-Núcleo metálico y perímetro de estructura mixta.

-Núcleo de hormigón y perímetro de estructura mixta.

-Núcleo y perímetro de hormigón.

Las ventajas encontradas a este último, que fue la opción elegida finalmente, son las siguientes:

-La transmisión de cargas verticales a través de pilares de hormigón de alta resistencia se realiza con menor coste que

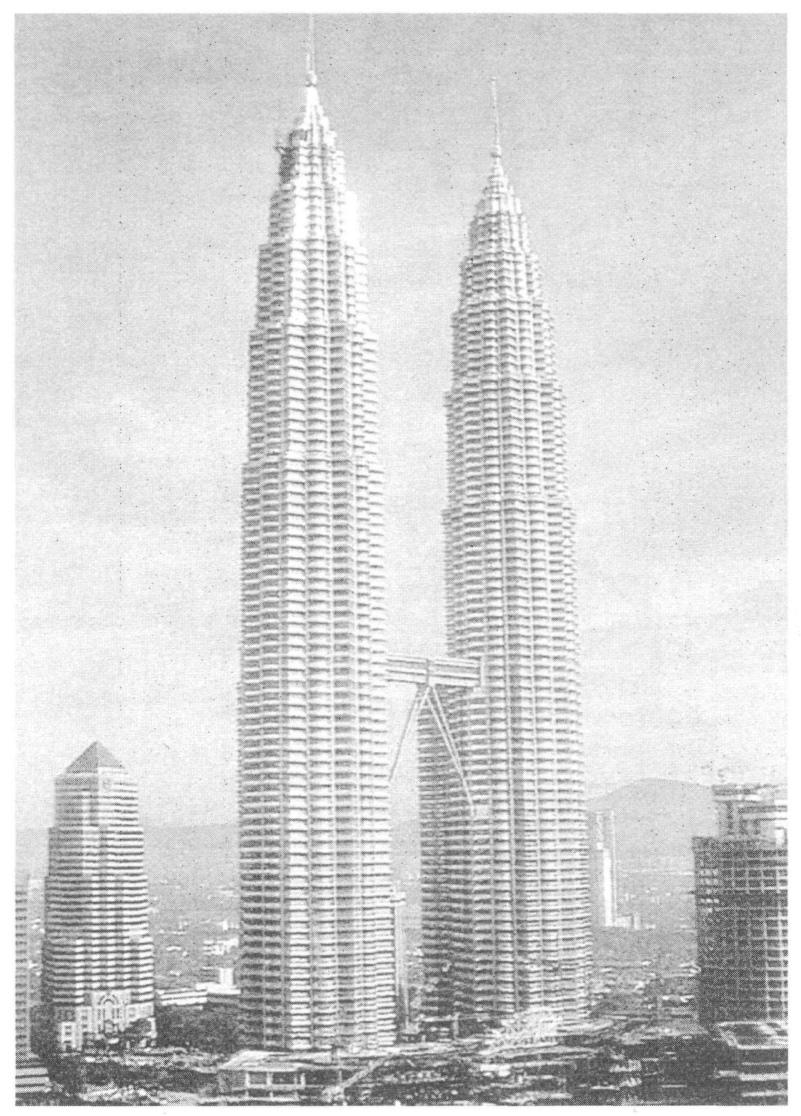

Foto 6 
con elementos metálicos, obteniéndose menores secciones que con hormigón normal y, por tanto, mayor superficie útil en el edificio.

-Los pilares perimetrales metálicos podían ser de menor sección para transmitir la misma carga vertical que los de hormigón, pero su rigidez frente a momentos flectores es menor, colaborando éstos más para resistir las acciones horizontales.

-Las pantallas de hormigón del núcleo tienen una doble misión:

. Servir de muros de compartimentación frente al fuego.

. Transmitir a la cimentación las cargas verticales.

-Las vigas perimetrales de hormigón tienen una unión fácil a los pilares de hormigón, colaboran en la rigidez frente a la acción del viento y no penalizan el tiempo de ejecución de forma significativa.

-El sistema de hormigón frente a las cargas laterales tiene una amortiguación mayor que el metálico. La respuesta dinámica de un sistema de hormigón será menor y más confortable para unas condiciones dadas de viento.

-Al aumentar la masa del edificio se prolonga el período de vibración y se mejora el confort.

-El hormigón era un material de posible consecución local, y con un coste relativamente bajo.

-El suministro de acero local en las cantidades necesarias para la ejecución de la estructura completa tenía una capacidad limitada, obligando a importar parte del mismo.

-Cualquier solución metálica requería amortiguamiento adicional, posiblemente en forma de dispositivo mecánico, lo que supone implicaciones de coste y de espacio.

-La solución de hormigón cumple los parámetros requeridos al proyecto.

-La estructura metálica obliga a mover en obra, mediante grúas, elementos pesados.

La cimentación del edificio está formada por una losa de 4,50 m de canto apoyada sobre 104 pilotes cuya sección tiene una dimensión de $1,20 \times 2,80 \mathrm{~m}$. La profundidad de los pilotes, variable para reducir los asientos diferenciales que pudieran provocar la inclinación de los estratos resistentes del terreno, se encuentra entre 40 y $105 \mathrm{~m}$.

El esquema estructural está formado, fundamentalmente, por un núcleo central, que sirve también como elemento conductor de las comunicaciones verticales en el edificio, y por una corona perimetral constituida por 16 pilares y las vigas respectivas que los unen en cada planta (Figura 19).

El núcleo, con planta cuadrada y dimensiones exteriores aproximadas de $23 \times 23 \mathrm{~m}$, está formado por unos muros cuyo espesor varía entre $0,75 \mathrm{~m}$ en las plantas inferiores y $0,35 \mathrm{~m}$ en la superior.

Los pilares perimetrales, separados entre 8 y $9 \mathrm{~m}$ cada uno del contiguo describen una circunferencia de $46 \mathrm{~m}$ de diámetro. La sección de los mismos, circular, varía entre 2,40 y $1,20 \mathrm{~m}$ a medida que se asciende por el edificio. En las vigas perimetrales se emplea el mismo hormigón, evitando así posibles errores y facilitando el proceso de puesta en obra mediante bombas.

El forjado está constituido por vigas metálicas de $0,45 \mathrm{~m}$ de canto, separadas $2,80 \mathrm{~m}$. Sobre ellas se sitúa una losa de $11,5 \mathrm{~cm}$ de espesor (una capa de 6,3 $\mathrm{cm}$ de espesor sobre un tablero de metal corrugado).

Además del forjado, la unión estructural entre el núcleo central y el sistema perimetral se efectúa mediante 4 vigas radiales (una en cada esquina) situadas en la planta $38^{\mathrm{a}}$ ocupando una doble planta mecánica.

Los edificios secundarios tienen una estructura formada por un "pórtico tubular cilíndrico" de $23 \mathrm{~m}$ de diámetro formado por pilares también circulares, con una sección entre 1,20 y $1,40 \mathrm{~m}$ de diámetro. Cada uno de estos edificios y el principal correspondiente se encuentran unidos mediante una estructura metálica.

Uniendo ambos edificios principales, entre las plantas $40^{\mathrm{a}}$ y $43^{\mathrm{a}}$ existe una pasarela de $58 \mathrm{~m}$ de longitud planteada como un sistema triarticulado, con dos vástagos que unen su centro con la planta $29^{\mathrm{a}}$ de cada edificio.

El hormigón dispuesto en los soportes, como se aprecia en la figura 20, varía en función de la altura, siendo de una resistencia a compresión de $80 \mathrm{MPa}$ entre la cimentación y la planta $23^{\mathrm{a}}$, de $60 \mathrm{MPa}$ entre ésta y la planta $61^{\mathrm{a}}$, y de 40 $\mathrm{MPa}$ el resto hasta la $84^{\mathrm{a}}$.

\section{Análisis de las soluciones estructurales y conclusiones}

Tras la descripción efectuada del sistema estructural planteado en cada uno de los edificios comentados, desarrollados todos ellos con HAR, este apartado se centrará en aquellos aspectos que permiten concluir ciertos criterios para su aplicación en futuros proyectos y construcciones.

Estando ya comentadas en el segundo punto de este escrito las ventajas de las estructuras ejecutadas con hormigón de alta resistencia, tanto frente a estructuras metálicas como frente a aquellas otras realizadas con hormigón normal ( $\leq 50 \mathrm{MPa}$ ), los criterios que se pueden recoger de 

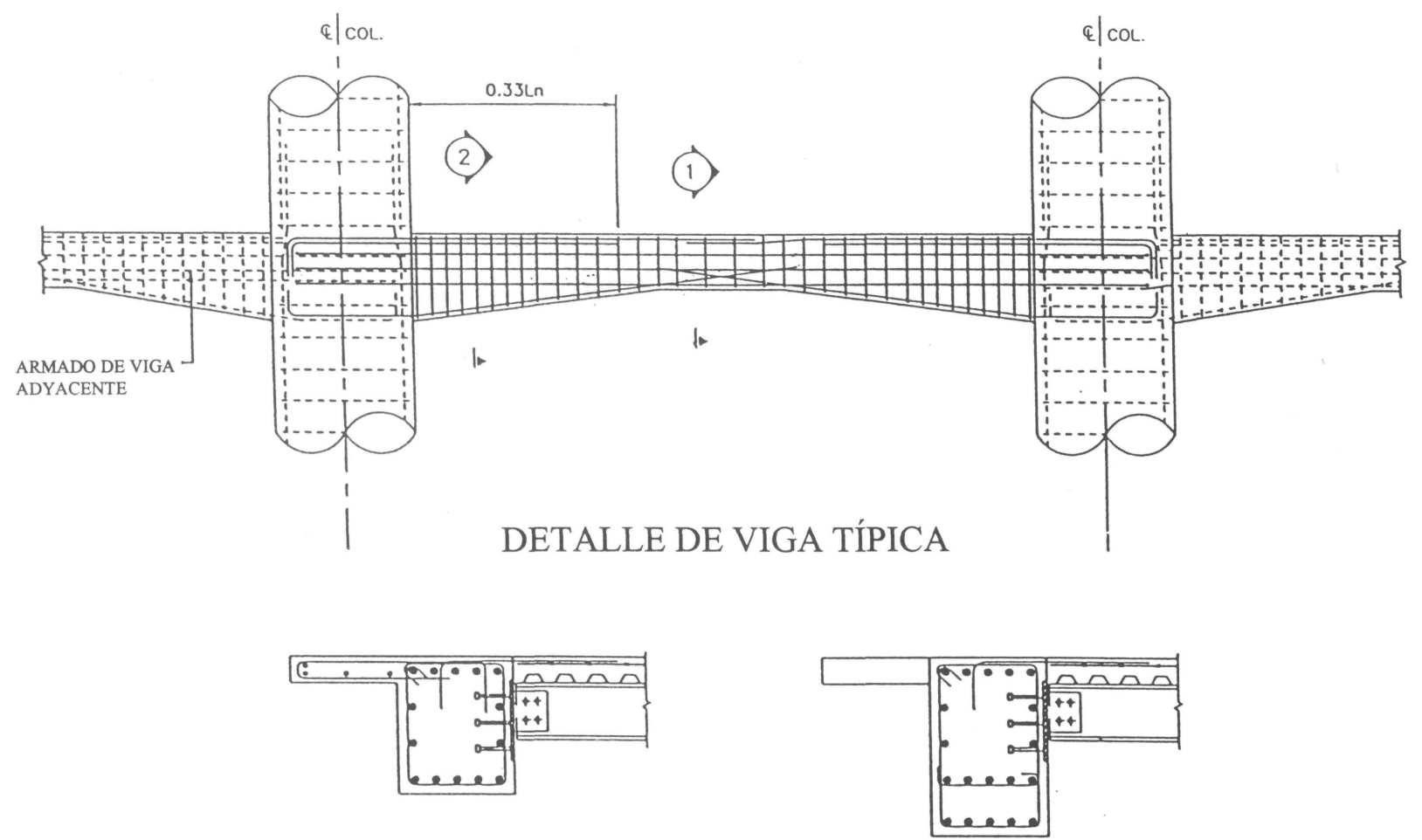

SECCIÓN 1

SECCIÓN 2

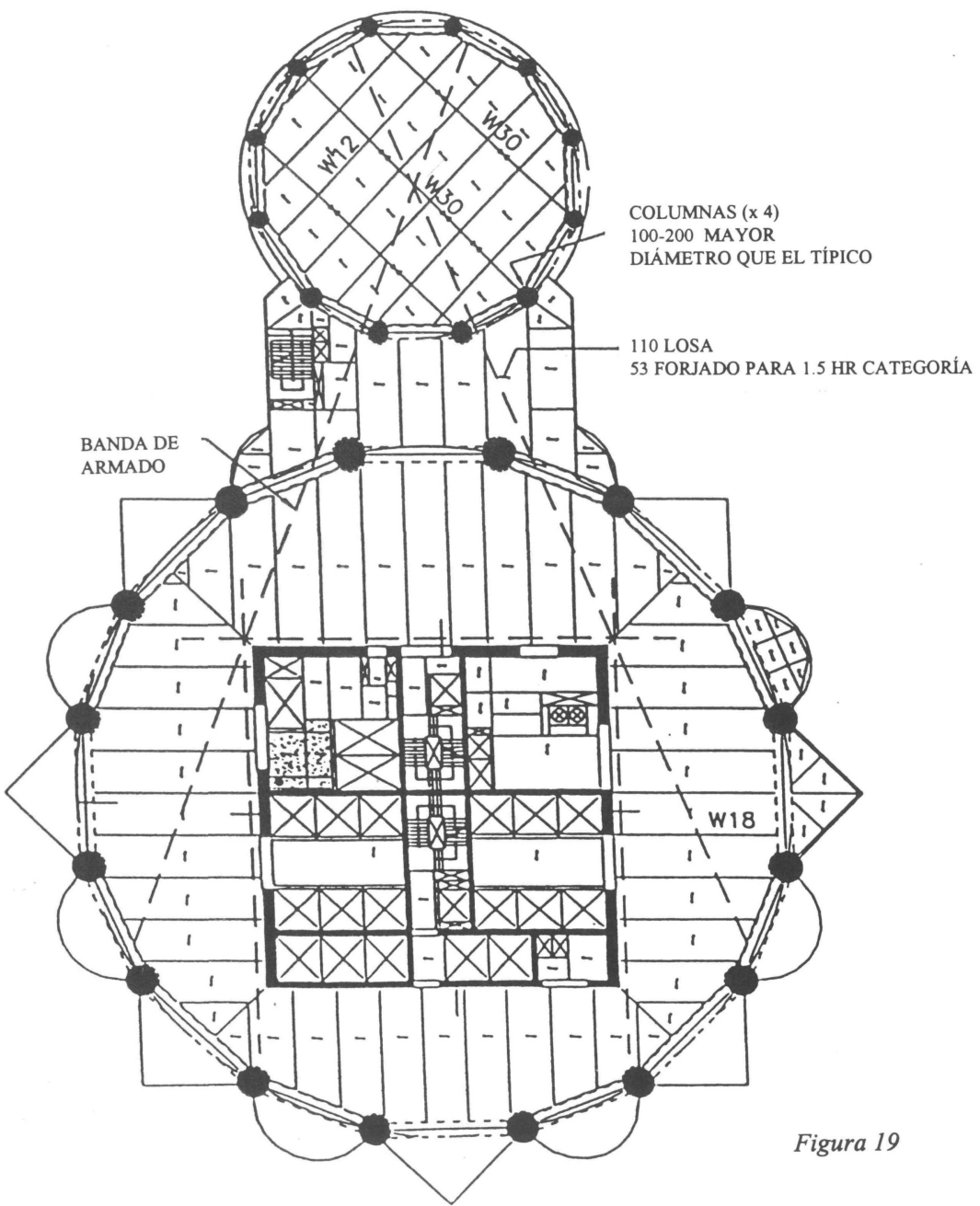




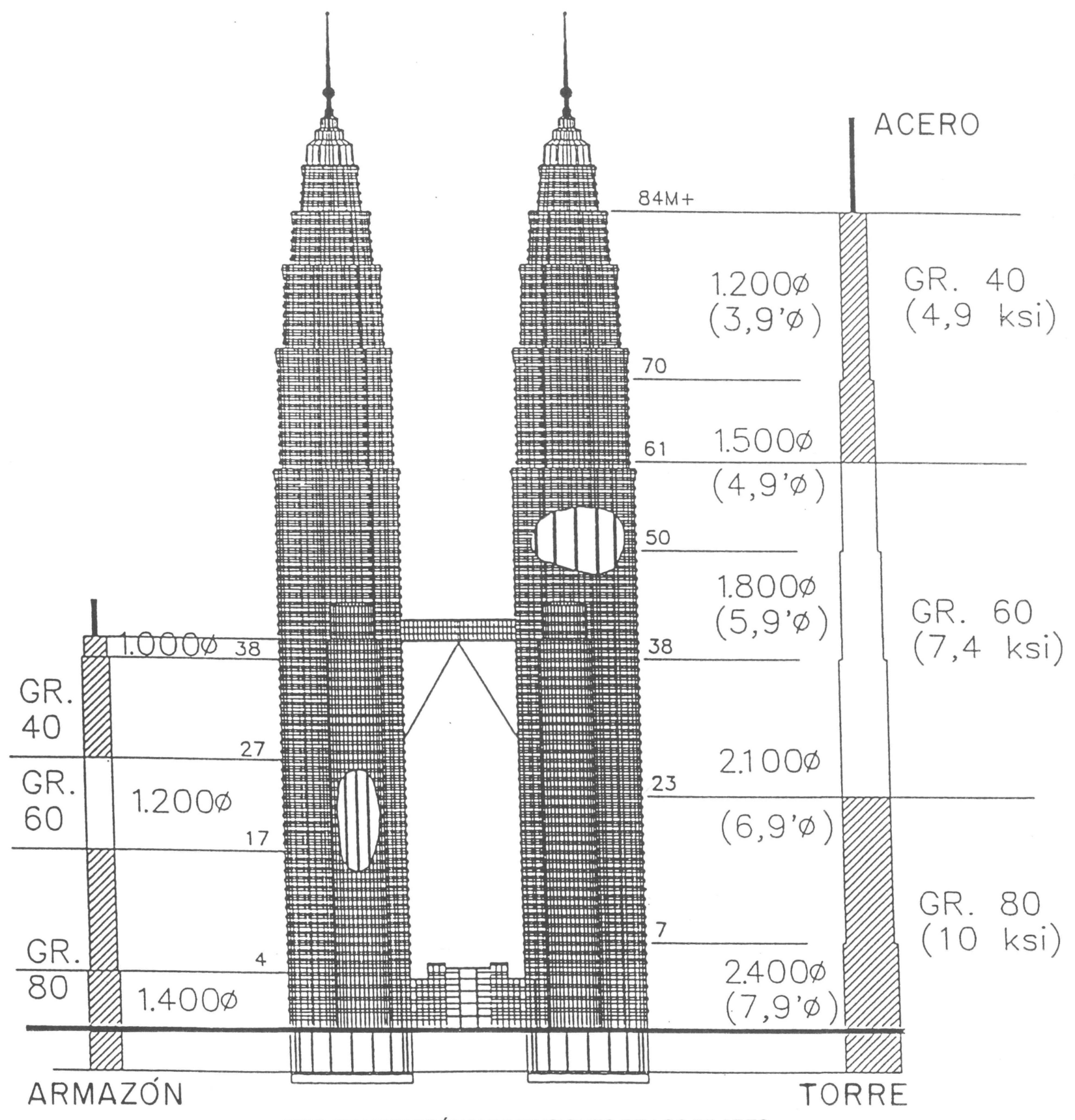

TIPO DE HORMIGÓN Y DIMENSIONES DE LOS PILARES

Figura 20

los ejemplos vistos en el apartado anterior son los siguientes:

-La tipología estructural responde a una solución "tubo en tubo", o bien a un núcleo central y un pórtico perimetral en la fachada, debiéndose este planteamiento en parte al tipo de edificio alto del que se trata y en parte al material utilizado.
-En edificios que superan las 80 plantas y los $400 \mathrm{~m}$ de altura se plantea una conexión entre los sistemas estructurales central y perimetral mediante unas vigas o cerchas radiales de gran canto.

-El esquema estructural y el dimensionamiento se encuentran diseñados de tal forma que las acciones horizontales debidas al viento $\mathrm{y} / \mathrm{o}$ al sismo sean absorbidas en su totali- 
dad por el núcleo central, o bien repartidas con el sistema perimetral sin que éste resista más de la mitad de aquéllas.

-El núcleo central, en todos los casos, se proyecta de hormigón armado.

-Los pilares que constituyen la corona resistente perimetral son de hormigón, metálicos o mixtos, combinándose en algunas ocasiones más de una de estas tipologías en el mismo edificio. Un aspecto muy importante que ha de tenerse en cuenta en el proyecto y cálculo de la estructura de estos edificios es el acortamiento producido por los esfuerzos axiles de compresión en los elementos verticales (muros del núcleo y pilares) y, sobre todo, los acortamientos diferenciales entre los mismos, ya que el efecto que producen sobre elementos estructurales horizontales es el mismo que pueden ocasionar asientos diferenciales de la cimentación, incrementando sobremanera los esfuerzos de flexión en sus extremos. En algunos casos la solución adoptada llega a ser la ejecución de las vigas radiales y los forjados con una cierta inclinación inicial alcanzando, a medio plazo, la horizontalidad deseada del elemento estructural.

-Las vigas perimetrales de hormigón se proyectan, por razones diversas y según las prioridades del cálculo y de la ejecución, con el mismo o con distinto tipo de hormigón que los pilares que unen.

-Los forjados están realizados con vigas interiores de hormigón armado o pretensado (acero postesado) o metálicas, sobre las que se extiende una losa de hormigón in situ única o situada sobre una chapa ondulada.

-El HAR se utiliza en elementos estructurales que resisten, básicamente, esfuerzos axiles de compresión (muros del núcleo de rigidización y pilares), estando proyectados los elementos horizontales (vigas y forjados) con hormigones de 25 a $35 \mathrm{MPa}$ de resistencia a compresión.

-El tipo de HAR empleado en los citados elementos verticales se encuentra normalmente entre 60 y $80 \mathrm{MPa}$ de resistencia a compresión, si bien este valor, en función del país en que se desarrolle el proyecto y/o la obra, será solicitado sobre probeta cilíndrica o probeta cúbica, con unas oscilaciones entre una y otra de un 10 a un $15 \%$.

-El tipo de hormigón utilizado en los mencionados elementos varía en función de la altura del edificio, reduciéndose la exigencia de sus características mecánicas a medida que se asciende.

Finalmente, debe subrayarse que, aunque en algunos edificios altos se ha empleado HAR, no debe olvidarse que en otros muchos se han utilizado y se utilizan con éxito hormigones normales con una resistencia de proyecto entre 40 y $50 \mathrm{MPa}$. Éstos permiten una obtención más fácil de las características mecánicas con un precio unitario inferior, manteniendo en gran medida las ventajas de rigidez, amortiguación, confort y coste que los primeros tienen frente a las estructuras metálicas.

\section{BIBLIOGRAFÍA}

ARCANGELI, A.: "Trianon skyscraper on the Mainzer Landstrasse in Frankfurt", L'industria italiana del cemento, $\mathrm{n}^{\circ} 716,1996$, págs. 860 a 871 .

CAMERON, CHISHOLM, NICOL Y OVE ARUP,: "La nueva sede della Banca del'Agricoltura e del'Industria a Perth", L'industria italiana del cemento, $n^{\circ} 708,1996$, págs. 221 a 223.

Council on Tall Buildings and Urban Habitat, Relación de los 100 edificios más altos del mundo.

GEHO, "Hormigones de alta resistencia. Fabricación y puesta en obra”, Boletín n²0, 1997.

GURUSAMY, K. y PRICE, W.F.: "The Petronas Towers, Kuala Lumpur: Beneficial use of High Strengh Concrete”, Multi-purpose High-rise Towers and Tall Buildings (Londres), 1997, págs. 383 a 396.

GÓMEZ HERMOSO, J.: "Últimas realizaciones internacionales en edificación con hormigón de alta resistencia (HAR). Análisis, conclusiones y tendencias", $1^{\circ}$ Symposium nacional de hormigón de altas prestaciones (Madrid), 1998, págs. 241 a 250.

HEGGER, J. y BURKHARDT, J.: "Structural strength and ductility of reinforced frame structures from High Strengh Concrete", 4th International Symposium on Utilization of High-strengh/Highperformance concrete (París), 1996, págs. 1505 a 1514.

HELD, M y KÖNIG, G.: "First Utilization of High-strengh Concrete in Germany", Structural Engineering International, vol. 2, nº 3,1992 , págs. 170 a 172 .

HU, Q. y ZHU, J.: "Utilization of High-strengh Concrete in Tall Buildings", The structural design of tall building, vol. $3, n^{\circ} 4$, 1994, págs. 269 a 274.

KOHN, PEDERSEN, FOX, SMITH, BROCHETTE, DAVIS y DRAKE, "A new skyscraper in Chicago at 311 South Wacker Drive", L'industria italiana del cemento, $n^{\circ} 670,1992$, págs. 628 a 639 .

KORISTA, D.S., SARKISIAN, M.P. y ABDELRAZAQ, A.K.: "Design and construction of China's tallest building: The Jin Mao Tower, Shanghai", Multi-purpose High-rise Towers and Tall Buildings (Londres), 1997, págs. 289 a 304.

McARTHUR, J., HENG, K. y VESEY, D.: "The Design and construction of Central Plaza and Their Interaction", 67th Regional Conference of Council on Tall Buildings and Urban Habitat, 1996, págs. 459 a 470.

MOHAMAD, H. y GABOR, P.: "Public Bank Building, Johor Bahru, Malaysia", Structural Engineering International, vol. 5, $\mathrm{n}^{\circ}$ 3, 1995, págs. 141 y 142 . 
MOHAMAD, H. y TONG, S.: "The Petronas Twin Towers, Malaysia", Structural Engineering International, vol. 7, $\mathrm{n}^{\circ}$ 3, 1997, págs. 153 a 156.

MONTI, G. y SANTUCCIO, S.: "The "Seismic" Tower in Charlotte, North Carolina, U.S.A.", L'industria italiana del cemento, $\mathrm{n}^{\circ} 713,1996$, págs. 584 a 597.

SANTACESARIA, M.: "The Pacific Tower: a new building at La Défense, Paris", L'industria italiana del cemento, $n^{\circ} 720,1997$, págs. 280 a 299.
THORNTON, C., MOHAMAD, H., HUNGSPRUKE, U. y JOSEPH, L.: "High Strengh Concrete for High-Rise Towers", 67th Regional Conference of Council on Tall Buildings and Urban Habitat, 1996, págs. 447 a 458.

YOLLES, M.S.: "New Developments in Tall Buildings", Structural Engineering International, vol. 2, n 3, 1992, págs. 175 a 177.

\section{publicación del IETCC/CSIC}

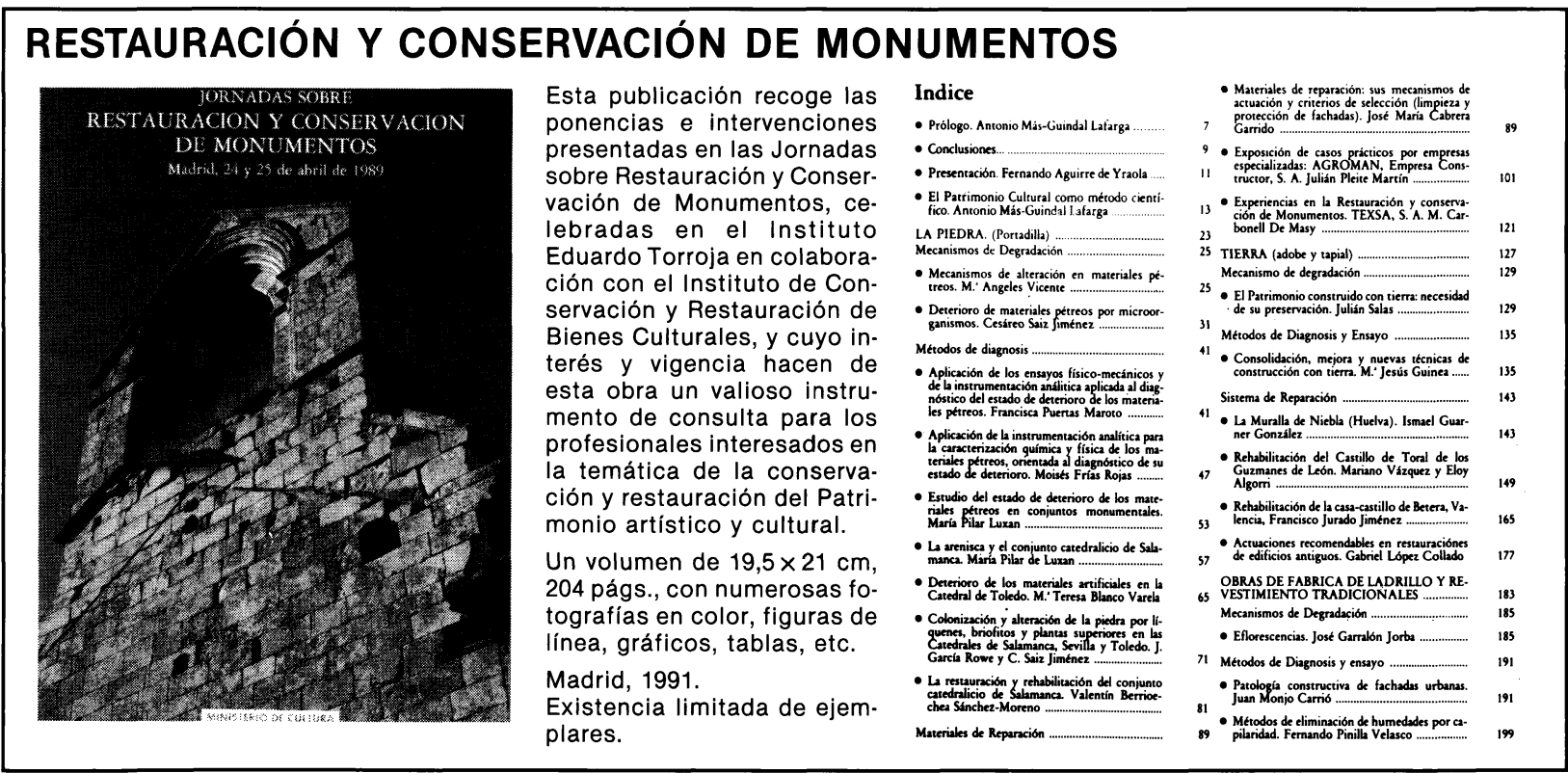

